H A R VAR D

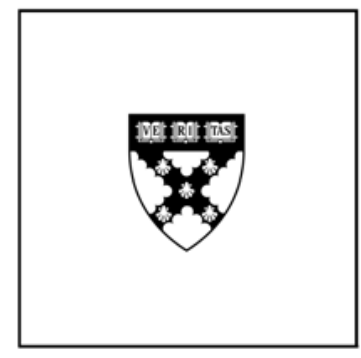

\title{
Why Do Intermediaries Divert Search?
}

\author{
Andrei Hagiu \\ Bruno Jullien
}

\section{Working Paper}

08-010 


\title{
Why Do Intermediaries Divert Search?*
}

\author{
Andrei Hagiu ${ }^{\dagger}$ and Bruno Jullien ${ }^{\ddagger}$ \\ First Draft: August 2007 \\ This Draft: April 20th 2010
}

\begin{abstract}
We analyze the incentives to divert search for an information intermediary who enables buyers (consumers) to search affiliated sellers (stores). We identify two original motives for diverting search (i.e. inducing consumers to search more than they would like): i) trading off higher total consumer traffic for higher revenues per consumer visit; ii) influencing stores' choices of strategic variables (e.g. pricing) once they have decided to affiliate. We characterize the conditions under which there would be no role for search diversion as a strategic instrument for the intermediary, thereby showing that it occurs even when the contracting space is significantly enriched. We then discuss several applications related to on-line and brick-and-mortar intermediaries.
\end{abstract}

Keywords: Market Intermediation, Search, Two-Sided Markets, Platform Design.

JEL Classifications: L1, L2, L8

\section{Introduction}

The previous literature on market intermediation (e.g. Spulber (1996) and (2007)) as well as conventional wisdom presume that one of the most important functions of market intermediaries is to reduce search costs for the parties they serve and that they create more value the larger such cost reductions they generate. This would seem to be true of both traditional, brick-and-mortar intermediaries (e.g. retailers, shopping malls, brokers, magazines) and "new economy" ones (e.g. Amazon, eBay, Google, iTunes, Yahoo!, etc.). Many of these intermediaries seem however, through some aspects of their design, to do quite the opposite of reducing search costs - and purposefully rather than by accident. For instance, e-commerce platforms increasingly use various forms of

*The authors thank Stefan Behringer, Emilio Calvano, Jacques Crémer, Jim Dana, Bill Rogerson, Mike Whinston and Alexander White for helpful discussions and comments, as well as participants to the CSIO-IDEI conference, EARIE, IOMS Beijing, ISM, Telecom ParisTech conference on ICT, WISE and to seminars at Berkeley Haas School of Business, Brunel, CREST-LEI, Harvard Business School, Hong Kong University, London Business School, Toulouse School of Economics, University College London, University Paris 1, University of Virginia.

${ }^{\dagger}$ Harvard University (HBS Strategy Unit), ahagiu@hbs.edu

¥Toulouse School of Economics (IDEI \& GREMAQ), bjullien@cict.fr 
recommender systems ${ }^{1}$ and contextual advertising in order to extend users' visits and shift - more or less subtly - their focus from the products they were initially looking for, towards "exploring" and "discovering" products they might be interested in - and eventually buy. And while these "diversion" tactics can take more varied and sophisticated forms online, they have long been used by offline intermediaries. For instance, shopping malls are designed to maximize the total distance consumers walk in the mall by locating anchor stores as far from each other as possible; supermarkets and other retail shops place the most sought-after items at the back of the store (Petroski (2003)).

This paper is the first attempt to examine - theoretically - the fundamental sources of an intermediary's incentives not to optimize the search process by which consumers find the stores (sellers) that the intermediary provides access to. The model we build is primarily inspired by e-commerce information intermediaries, but the insights derived and their applicability are more general as discussed in section 5. Examples of such intermediaries include Bing Cashback, Kaboodle.com and ThisNext.com: given the exploding variety of online shopping destinations, they create value by aggregating e-commerce information in one place and directing consumers to third-party online shopping sites most likely to suit their preferences. The intermediaries' revenues come from the affiliated third-party e-commerce sites, which typically pay fixed fees per consumer visit (per click) or per sales generated.

In our model, two types of consumers must use an intermediary to access two stores (sellers), each of which is preferred by one of the two consumer types. Consumers can only visit stores sequentially and each visit is costly. The intermediary has superior information about the match between consumers' preferences and the stores; its revenues are made up of fixed fees paid by each store for each consumer visit received. In this context, the intermediary may elect to divert consumers' search - i.e. direct them first to their least preferred store - depending on the structure of the revenues it derives from stores and on the shape of the distribution of consumer search costs. Importantly, diverting search is different than increasing unitary search costs (i.e. search costs per visit): in our model, as in reality, intermediaries would always want to decrease consumers' unitary search costs if they could.

We tackle several important questions regarding the design of such information services by intermediaries. Under what conditions do intermediaries find it profitable not to maximize the effectiveness of their information service, i.e. to divert consumers' search process? What are the underlying motivations for diverting search? And if some form of search diversion is profit-maximizing, can it not be replicated by other contractual instruments that intermediaries might have at their disposition?

\footnotetext{
${ }^{1}$ According to a Forrester Research study, consumer online spending was $\$ 220$ billion in 2006 and recommender systems could account for 10 to 30 percent of any online retailer's sales ("Click here for the upsell," Business 2.0, July 11th 2007).
} 
We identify two key and original motivations for search diversion by the intermediary. ${ }^{2}$ First and most fundamental, due to a failure of the Coase theorem, consumers do not internalize ex-ante all the externalities that their search activities generate. In particular, they do not account for the gains from trade bestowed on all of their potential trading partners - stores - when deciding to perform a search through the intermediary, which may lead to "insufficient" search. Since the intermediary derives revenues whenever consumers transact with stores, it has an incentive to introduce some noise in the search process, i.e. to divert search. In turn, consumers anticipate this and might be less likely to use the intermediary's service in the first place. Therefore, the intermediary has to trade off higher total consumer "traffic" against a higher average number of searches per visitor.

Second, an intermediary can use search diversion as an instrument to influence the strategic choices (pricing in particular) made by affiliated stores. Such indirect control is desirable for the intermediary since individual stores do not fully internalize the effect of their strategic decisions on total consumer demand for the intermediary's service. By altering the composition of the demand faced by each store, search diversion can force stores to lower their prices, thereby increasing the surplus left to consumers (even though search diversion by itself lowers consumer utility) and ultimately their traffic to the intermediary.

It is then natural to ask: could one not eliminate the need for search diversion by other pricing or contractual instruments that intermediaries might have at their disposition? We show that the only case in which the need for search diversion disappears entirely is when the intermediary can charge consumers access fees, subsidize their second search and fully control store prices. ${ }^{3}$ By contrast, adding only one or two of these additional contractual instruments is insufficient to eliminate search diversion incentives.

Furthermore, our analysis implies that search diversion may be necessary for welfare maximization, and that it is unlikely to be eliminated by competition. Indeed this is a pervasive phenomenon and we explain in the discussion section how our model can easily be adapted to encompass other industry settings, such as media, shopping malls or department stores.

\section{Related literature}

Our paper contributes both to the established economics literature on market intermediation (Biglaiser (1993), Gehrig (1993), Rubinstein and Wolinsky (1987), Spulber (1996), Rust and Hall (2001)) and to the more recent and quickly growing one on two-sided markets (Caillaud and Jullien (2001, 2003), Evans (2003), Rochet and Tirole (2003), Armstrong (2006), Hagiu (2006)). The former was mostly focused on traditional intermediaries, who buy and resell goods, while the latter was

\footnotetext{
${ }^{2}$ More conventional motives related to price discrimination are not adressed in this paper (see our 2008 IDEI Working Paper).

${ }^{3}$ The latter condition is equivalent to assuming complete vertical integration between the intermediary and the stores. It also includes the ability to commit ex-ante on the prices.
} 
motivated by the rising importance of "new economy" intermediaries (called "two-sided platforms"), who connect buyers and sellers and provide matching, price discovery, certification, advertising and other informational services, without (usually) assuming full control over the transactions enabled. ${ }^{4}$ In both of these strands of research however, intermediaries are presumed to create value by reducing search and/or transaction costs and the "technologies" which enable them to do so are taken as exogenously given.

To the best of our knowledge, ours is the first paper to study formally the design of information services by intermediaries and to show that their incentives with respect to search effectiveness are fundamentally driven by the structure of the revenues they derive from the parties they serve. ${ }^{5}$ By contrast, most of the economics literature on two-sided markets to date has focused on the choice of pricing structures by two-sided platforms as a function of various industry factors - e.g. relative strengths of the indirect network effects on each side, relative demand elasticities - and has largely ignored two-sided platform design issues (One exception is Parker and Van Alstyne (2008), which focuses on platforms' choice of openness).

Baye and Morgan (2001) have pointed out the obstacles to extracting surplus from consumers and firms due to price externalities in the context of a price search engine, while Ellison and Ellison (2009) discuss the fact that some search friction may raise retailers' prices and profits. Armstrong, Vickers and Zhou (2009) mention the possibility that an intermediary distorts the search process so as to induce prominence when its revenue comes solely from sellers. Our paper departs from this setting in that we abstract from the issue of price competition between sellers, which is their main focus. In our model, even a platform maximizing total welfare may divert search. Rayo and Segal (2009) analyze the incentives of a "sender" to add noise to the signal transmitted to a "receiver" depending on the profitability of the signal to the sender. While the broad theme (information service design) is related to ours, the underlying mechanisms at work in their paper are quite different: there are no search externalities involved and the "second side" (advertisers) does not make strategic decisions (e.g. pricing) which can be influenced by the information service.

Finally, since the design of an information service by an intermediary can be considered as a form of matching mechanism design, our work is also related to the literature on market design (surveyed in Roth (2002) and (2008), Roth and Sotomayor (1990)). There are three main differences between our paper and this literature. First, while the market design litterature attempts to derive efficient (from a total social welfare perspective) and/or stable matching mechanisms, we study information service design by a profit-maximizing platform. Second, "matches" in our model (i.e. consumers visiting stores) are not substitutes, as they are in the market design literature (e.g.

\footnotetext{
${ }^{4}$ Hagiu (2007) contains a unifying framework for analyzing these two forms of intermediation as two extremes along a continuum.

${ }^{5}$ There is a very recent literature focusing specifically on the design of search engines, which bears some aspects in common with our approach. See White (2008), de Cornière (2010).
} 
new medical school graduates taking posts as interns or residents at hospitals). Third, our model encompasses both non-price and price-matching mechanisms allowing for endogenous participation, and we investigate the possibility that the matching mechanism indirectly affects transfer prices within matched pairs, which to our knowledge is novel. ${ }^{6}$

The remainder of the paper is organized as follows. In the next section we set up our model in its most general form. Section 3 analyzes the intermediary's incentives to divert search, first assuming store prices are exogenously fixed and then allowing them to be endogenously determined. In section 4 we examine the effect of additional contractual instruments on the intermediary's incentives to divert search. Section 5 discusses welfare considerations and other real-world contexts to which our model applies. Section 6 concludes.

\section{Model set-up}

To fix ideas, it is useful to think of our model as a stylized representation of an online recommender system for commercial products, such as Bing Cashback, Kaboodle.com, ThisNext.com, etc. The main service offered by these sites to consumers is directing them to third-party online stores where they are most likely to find products which best suit their (revealed) preferences. Preferences are inferred by the recommenders based on users' profiles, past browsing and shopping history and comparison with users that have similar profiles. The recommenders derive revenues from the third-party online stores they generate leads for: either "per-click" (i.e. fixed fees per user who "jumps" to the third-party's site directly from the recommender's site) or a percentage of realized sales. Importantly, users can access and use the recommenders' sites for free.

In our model there is a monopoly intermediary which allows a unit mass of consumers to access two third-party stores (1 and 2). Consumers must use the intermediary to access the stores. The intermediary knows which store best fits a given consumer's preferences (in a sense to be defined precisely below) and thus has an informational advantage over consumers, who can only learn the fit through costly search.

\subsection{Consumers and stores}

Consumers differ along two dimensions: search costs and preferences for stores. Along the first dimension, consumers are differentiated by the search cost $c$ they incur each time they visit a store. They can only visit the two stores sequentially (and they perform at most two rounds of search). We assume that $c$ is distributed on $\mathbb{R}_{+}$according to a twice continuously differentiable

\footnotetext{
${ }^{6}$ Hatfield and Milgrom (2005) contains one of the first attempts to include contracts in matching games.
} 
cumulative distribution function $F$. Throughout the paper, the density function $f($.$) is assumed to$ be log-concave.

Along the second dimension, there are two types of consumers. Type 1 consumers make up a fraction $\alpha_{1}$ of the population and prefer store 1 over store 2 (in a sense that we define precisely below) while type 2 consumers make up the remaining fraction $\alpha_{2}=1-\alpha_{1}$ and prefer store 2 over store 1 . The distribution of the two types in the consumer population is independent of the distribution of search costs.

Upon a visit to a store $j$, a consumer may decide to buy the product sold by that store. Her valuation is unknown prior to the visit but is learnt upon inspection of the store and its product. The valuations of type $i \in\{1,2\}$ consumers for the product sold by store $i$ are distributed according to cumulative distribution function $G^{H}($.$) , while their valuations for store j \neq i$ are distributed according to cumulative distribution function $G^{L}($.$) . Although we investigate this possibility in a$ companion paper (Hagiu and Jullien (2010)), in this paper there is no substitutability nor arity between stores so that valuations are independent across consumers and stores. A consumer of type $i$ derives ex-ante expected utility $u^{k}(p) \equiv \int_{v \geq p}(v-p) d G^{k}(v)$ from store $j$ when the latter charges a price $p$, where $k=H$ if $i=j$ and $k=L$ if $i \neq j$.

Denoting $m$ the stores' marginal cost, let us define

$$
R^{H}(p) \equiv(p-m)\left(1-G^{H}(p)\right) \quad \text { and } \quad R^{L}(p) \equiv(p-m)\left(1-G^{L}(p)\right)
$$

the average revenues that a store derives from visiting consumers for whom it is the favorite, respectively less preferred, store. For convenience, we assume that $R^{H}($.$) and R^{L}($.$) are strictly$ concave, continuously differentiable functions. The preference for store $i$ by type $i$ consumers is reflected in the following assumption: ${ }^{7}$

$$
p^{H} \equiv \arg \max _{p} R^{H}(p)>p^{L} \equiv \arg \max _{p} R^{L}(p)
$$

Thus store $i$ would charge a higher price for type $i$ consumers. We also assume that this preference is strong enough so that:

Assumption 1: $u^{H}\left(p^{H}\right)>u^{L}\left(p^{L}\right)$.

Assumption 1 ensures that type $i$ consumers prefer shopping at store $i$ relative to store $j$ for any prices $p_{i}$ and $p_{j}$ on the support $\left[p^{L}, p^{H}\right]$. Note that when a store's price maximizes the store's profit for some fixed proportion of consumers of each type, then it lies in the interval $\left[p^{L}, p^{H}\right]$. We assume this is the case throughout the paper and thus restrict attention to:

\footnotetext{
${ }^{7}$ The assumption on optimal monopoly prices follows if $G^{H}($.$) has a lower hazard rate than G^{L}($.$) .$
} 
Assumption 2: For $i=1,2: p^{H} \geq p_{i} \geq p^{L}$.

In what follows, we will consider two cases, depending on whether store prices are exogenously given or endogenously determined in our model.

The case with exogenous store prices (treated in section 3.1) corresponds to contexts in which store prices are determined by channels other than the information intermediary we are focusing on or contexts in which the stores choose their prices before the intermediary makes its design decisions. For instance, some large electronics retailers affiliated with Bing Cashback (e.g. Best Buy) have other, larger sales channels, so that the consumer demand brought by Bing is too small to affect their pricing decision. And even for smaller retailers, for whom Bing Cashback is a significant traffic driver, they might be unable to adjust their prices in response to design changes by Bing.

In the case with endogenous store prices (treated in section 3.2 below), stores make their pricing decisions after observing the intermediary's design decision but store prices are unobservable by consumers prior to engaging in search (consumers form however rational expectations about these prices). This corresponds to contexts in which the information intermediary we consider is the primary sales channel for the affiliated stores and the latter can adjust prices in response to design changes by the intermediary (e.g. small online sites affiliated with Bing Cashback, Kaboodle or ThisNext).

\subsection{The intermediary and the consumer search process}

When a consumer arrives at the intermediary, the latter assesses the consumer's type (1 or 2$)$ and directs her to one of the two stores. The consumer incurs search cost $c$ to visit that store and observes whether it is her preferred store or not, the price and her valuation for the store's product. She buys it if the price is lower than the valuation. Then the consumer decides whether or not to incur the cost $c$ again in order to visit the second store. We assume that at the second visit the consumer is automatically sent to the store she has not visited in the first round (thus, the consumer knows whether the second store is her favorite or least favorite before going there).

We denote by $q_{i}$ the probability that the intermediary sends a consumer of type $i$ to store $i$ for the first visit. Thus, we allow the intermediary to discriminate the provision of its information service by consumer type (which is quite plausible given the information available to the online intermediaries we have in mind). Throughout the paper, our focus will be on the intermediary's choices of $q_{i}$ 's. In particular, we say that the intermediary "diverts" consumers of type $i$ whenever $q_{i}<1$. The lower $q_{i}$, the more diversion there is.

In principle, the intermediary could be receiving at least two types of variable fees from affiliated stores: "per click" (i.e. per consumer visit) fees or a percentage of sales. For the sake of concision, we focus on the case in which the intermediary receives an exogenously fixed "per click" fee $r_{i}$ for 
each consumer visit at store i. But the nature of the variable fees used, and whether they are endogenous or exogenous, does not affect the substance of our result, as we show formally in the companion paper.

\subsection{Timing}

As mentioned above, we treat two cases. First, when store prices are exogenous and publicly known, the timing of decisions is as follows: 1 ) the intermediary publicly commits to $q_{1}$ and $q_{2} ; 2$ ) consumers observe $q_{1}$ and $\left.q_{2} ; 3\right)$ consumers decide whether or not to use the intermediary's information service, engage in the search process and make their purchase decisions when arriving at each store.

Second, when store prices are endogenously determined, the timing of decisions is as follows: 1) the intermediary publicly commits to $q_{1}$ and $q_{2} ; 2$ ) stores choose their prices $p_{1}$ and $p_{2}$ simultaneously and non-cooperatively; 3) consumers observe $q_{1}$ and $q_{2}$ and form rational expectations over store prices, which they do not observe prior to search; 4) consumers decide whether or not to use the intermediary's information service, engage in the search process and make their purchase decisions when arriving at each store.

\section{Search diversion}

\subsection{Store prices are exogenous}

Throughout this section, we assume store prices are exogenously fixed at $p_{1}$ and $p_{2}$ : as mentioned above, this may be because stores choose their prices based on other, more important sales channels than the intermediary we focus on; or because these prices are publicly advertised before the intermediary chooses $q_{1}$ and $q_{2}$ and therefore known by consumers before engaging in search.

Recall that assumption 1 implies $u^{H}\left(p_{i}\right)>u^{L}\left(p_{j}\right)$ for $i \neq j \in\{1,2\}$, so that consumers of type $i$ prefer shopping at store $i$ over shopping at store $j$.

Consider consumers of type $i$. Those with "low" search costs - i.e. with $c \leq u^{L}\left(p_{j}\right)$ - will visit both stores irrespective of where the intermediary directs them for their first visit. Consequently, the intermediary receives $\left(r_{1}+r_{2}\right)$ total revenues for each such consumer. Type $i$ consumers with "high" search costs - i.e. $c>u^{H}\left(p_{i}\right)$ - do not visit the intermediary at all. Finally, type $i$ consumers with intermediate search costs - i.e. $u^{L}\left(p_{j}\right) \leq c \leq u^{H}\left(p_{i}\right)$ - visit both stores if the intermediary first directs them to store $j$ (which happens with probability $\left(1-q_{i}\right)$ ) but stop after the first visit if the intermediary first directs them to store $i$ (their favorite). Their expected net utility is:

$$
u^{H}\left(p_{i}\right)+\left(1-q_{i}\right) u^{L}\left(p_{j}\right)-\left(2-q_{i}\right) c
$$


and each such consumer generates expected revenues $\left(r_{i}+\left(1-q_{i}\right) r_{j}\right)$ for the intermediary.

Consequently, total "traffic" to the intermediary by consumers of type $i$ is $\alpha_{i} F\left(u_{i}\right)$, where:

$$
u_{i} \equiv u\left(p_{i}, p_{j}, q_{i}\right) \equiv \frac{u^{H}\left(p_{i}\right)+\left(1-q_{i}\right) u^{L}\left(p_{j}\right)}{2-q_{i}}
$$

And the expression of the intermediary's total revenues is:

$$
\begin{aligned}
\Pi^{I}\left(q_{1}, q_{2}\right)= & \underbrace{\alpha_{1}\left\{\left(r_{1}+r_{2}\right) F\left(u^{L}\left(p_{2}\right)\right)+\left[r_{1}+\left(1-q_{1}\right) r_{2}\right]\left[F\left(u_{1}\right)-F\left(u^{L}\left(p_{2}\right)\right)\right]\right\}}_{\text {revenues from type } 1 \text { consumers }} \\
& +\underbrace{\alpha_{2}\left\{\left(r_{1}+r_{2}\right) F\left(u^{L}\left(p_{1}\right)\right)+\left[r_{2}+\left(1-q_{2}\right) r_{1}\right]\left[F\left(u_{2}\right)-F\left(u^{L}\left(p_{1}\right)\right)\right]\right\}}_{\text {revenues from type } 2 \text { consumers }}
\end{aligned}
$$

In what follows we assume the intermediary can choose any $\left(q_{1}, q_{2}\right)$ within the unit square, i.e. it can perfectly separate the information services provided to the two types of consumers.

Note that in expression (1) above, $q_{1}$ only affects the first term (revenues from type 1 consumers) whereas $q_{2}$ only affects the second term (revenues from type 2 consumers). Also, this expression contains the key tradeoff involved in diverting search. Consider type 1 consumers for example. Lowering $q_{1}$ (increasing diversion) reduces total traffic by type 1 consumers to the intermediary by lowering $u_{1}$, but at the same time it increases the revenues obtained from infra-marginal type 1 consumers (more precisely, those with $c \in\left[u^{L}\left(p_{2}\right), u^{H}\left(p_{1}\right)\right]$ ). The tradeoff is illustrated in the following figure:

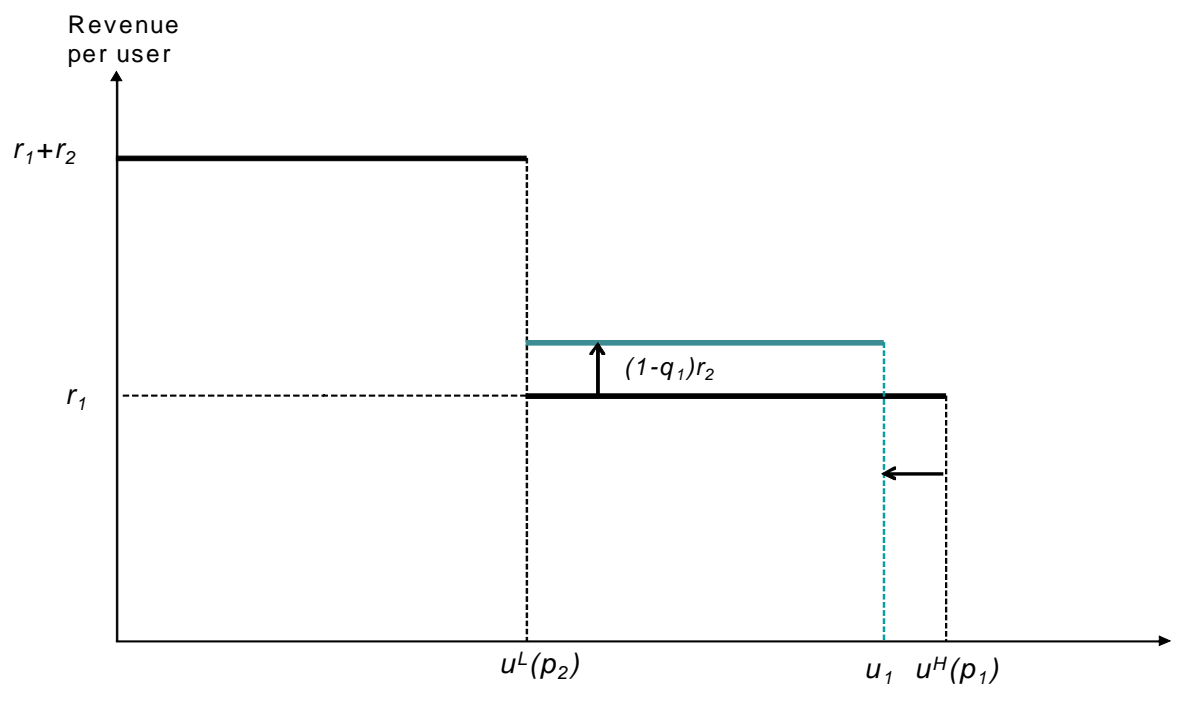

Specifically, this figure shows the effect of search diversion, i.e. of going from $q_{1}=1$ to $q_{1}<1$. 
Maximizing (1) over $\left(q_{1}, q_{2}\right)$ yields the following proposition, which contains our baseline results.

Proposition 1 a) The monopoly intermediary's optimal choice of search effectiveness $q_{i}^{*}$ is increasing in $\frac{r_{i}}{r_{j}}$ for $i \neq j \in\{1,2\}$

b) The intermediary diverts type $i$ consumers (i.e. sets $q_{i}^{*}<1$ ) if and only if:

$$
\frac{r_{j}}{r_{i}}>\frac{f\left(u^{H}\left(p_{i}\right)\right)\left(u^{H}\left(p_{i}\right)-u^{L}\left(p_{j}\right)\right)}{F\left(u^{H}\left(p_{i}\right)\right)-F\left(u^{L}\left(p_{j}\right)\right)}
$$

c) If $F$ is stricly concave then at least one consumer type $i \in\{1,2\}$ is diverted, i.e. $q_{i}^{*}<1$. If $F$ is strictly convex then at least one consumer type is not diverted.

Proof. In the appendix.

Parts a) and b) in Proposition 1 reflect the key mechanism at work in our baseline model. In response to an increase in revenues derived from store $i$ relative to store $j$, the intermediary reduces search diversion for type $i$ consumers (i.e. increases $q_{i}^{*}$ ). This is because type $i$ consumers prefer store $i$, therefore if that store yields higher revenues relative to store $j$, the intermediary has less of an incentive to divert type $i$ consumers to store $j$.

The right hand side of (2) has a straightforward interpretation. At $q_{i}=1$, all type $i$ consumers with $c \leq u^{H}\left(p_{i}\right)$ visit the intermediary and only those with $c \leq u^{L}\left(p_{j}\right)$ visit both stores. We now ask whether the intermediary has any interest in slightly lowering $q_{i}$ by a very small amount $\varepsilon$. This has two effects on the intermediary's profits. The first effect is negative since the intermediary loses the traffic of type $i$ consumers with the highest search costs. The absolute value of this effect is $r_{i}\left[F\left(u^{H}\left(p_{i}\right)\right)-F\left(u_{i}(1-\varepsilon)\right)\right]$, which is approximately equal to $r_{i} \varepsilon\left[u^{H}\left(p_{i}\right)-u^{L}\left(p_{j}\right)\right] f\left(u^{H}\left(p_{i}\right)\right)$. The second effect is positive since now a fraction $\varepsilon$ of all (inframarginal) type $i$ consumers with $c \in\left[u^{L}\left(p_{j}\right), u_{i}(1-\varepsilon)\right]$ also visit store $j$ - their less preferred store. The magnitude of this effect is approximately $r_{j} \varepsilon\left[F\left(u^{H}\left(p_{i}\right)\right)-F\left(u^{L}\left(p_{j}\right)\right)\right]$. Comparing the two effects yields exactly condition $(2)$.

The RHS in (2) can also be rewritten:

$$
\frac{f\left(u^{H}\left(p_{i}\right)\right)\left(u^{H}\left(p_{i}\right)-u^{L}\left(p_{j}\right)\right)}{F\left(u^{H}\left(p_{i}\right)\right)} / \frac{F\left(u^{H}\left(p_{i}\right)\right)-F\left(u^{L}\left(p_{j}\right)\right)}{F\left(u^{H}\left(p_{i}\right)\right)}
$$

where the numerator is the elasticity of type $i$ consumer traffic to the intermediary $\left(F\left(u_{i}\right)\right)$ with respect to $q_{i}$ and evaluated at $q_{i}=1$, while the denominator is the proportion of consumers who would not voluntarily conduct the second search. The lower this ratio, the lower the relative cost of search diversion and thus the higher the incentive for the intermediary to divert search. 
Search diversion becomes more attractive for the intermediary when the density of marginal consumers decreases with total demand, i.e. when $F$ is concave. Indeed, in this case the amount of traffic by type $i$ consumers lost by lowering $q_{i}$ below 1 tends to be small compared to the increase in store visits by infra-marginal type $i$ consumers. Then search diversion is profitable at least for the group of consumers who prefer the less "profitable" store (i.e. $i$ such that $r_{i} \leq r_{j}$ ). Notice that for $r_{1}=r_{2}$ both types are diverted. The reverse holds when the density of marginal consumers increases with total demand, i.e. $F$ is convex. Then the cost of introducing search diversion is relatively high and at least the consumers who prefer the more profitable store are not diverted.

Finally, as an illustration, consider the case in which $F($.$) is uniform with constant density f$. Then exactly one consumer type $i$ is diverted and there is maximal diversion for this type, i.e. $q_{i}^{*}=0$, while the other consumer type receives a perfect information service, $q_{j}^{*}=1$. Indeed, the intermediary's revenues attributable to type $i$ consumers are:

$$
\alpha_{i} f\left\{\left(r_{i}+r_{j}\right) u^{L}\left(p_{j}\right)+\left[r_{i}+\left(1-q_{i}\right) r_{j}\right] \frac{u^{H}\left(p_{i}\right)-u^{L}\left(p_{j}\right)}{2-q_{i}}\right\}
$$

and their derivative with respect to $q_{i}$ is $\frac{\alpha_{i} f\left(r_{i}-r_{j}\right)\left[u^{H}\left(p_{i}\right)-u^{L}\left(p_{j}\right)\right]}{\left(2-q_{i}\right)^{2}}$. Thus, consumers who prefer the less profitable store are always diverted to the more profitable store.

\subsection{Store prices are endogenous}

When store prices are endogenously determined, stores choose their prices $p_{1}$ and $p_{2}$ after the intermediary publicly commits to $q_{1}$ and $q_{2}$. Consumers however only observe these prices when they visit the stores - thus, they have to make their search decisions based on rational expectations of store prices.

Consumer traffic at store $i$ is made up of two segments corresponding to the two consumer types. Since store $i$ makes $\left[R^{H}\left(p_{i}\right)-r_{i}\right]$ in revenues per type $i$ consumer visit and $\left[R^{L}\left(p_{i}\right)-r_{i}\right]$ per type $j$ consumer visit, its profits are: ${ }^{8}$

$$
\begin{aligned}
& {\left[R^{H}\left(p_{i}\right)-r_{i}\right] \underbrace{\alpha_{i} F\left(u\left(p_{i}, p_{j}, q_{i}\right)\right)}+\left[R^{L}\left(p_{i}\right)-r_{i}\right] \underbrace{\alpha_{j}\left[q_{j} F\left(u^{L}\left(p_{i}\right)\right)+\left(1-q_{j}\right) F\left(u\left(p_{j}, p_{i}, q_{j}\right)\right)\right]}} \\
& \text { store } i \text { 's traffic by store } i \text { 's traffic by } \\
& \text { type } i \text { consumers type } j \text { consumers }
\end{aligned}
$$

Since consumers make their search decisions based on rational expectations of store prices, which

\footnotetext{
${ }^{8}$ Recall that $u_{i}\left(p_{i}, p_{j}, q_{i}\right) \equiv \frac{u^{H}\left(p_{i}\right)+\left(1-q_{i}\right) u^{L}}{\left.2-q_{i}\right)}$
} 
have to be fulfilled in equilibrium, the equilibrium prices $\left(p_{1}^{*}, p_{2}^{*}\right)$ chosen by the stores solve:

$$
p_{i}^{*}=\arg \max _{p}\left\{R^{H}(p)+\beta_{i}^{*} R^{L}(p)\right\} \text { for } i \neq j \in\{1,2\}
$$

where $\beta_{i}^{*} \equiv \frac{\alpha_{j}}{\alpha_{i}} \frac{\left[q_{j} F\left(u^{L}\left(p_{i}^{*}\right)\right)+\left(1-q_{j}\right) F\left(u\left(p_{j}^{*}, p_{i}^{*}, q_{j}\right)\right)\right]}{F\left(u\left(p_{i}^{*}, p_{j}^{*}, q_{i}\right)\right)}$.

Equation (4) implicitly defines $p_{i}^{*}\left(q_{1}, q_{2}\right)$ for $i=1,2$. We then obtain the following lemma, proven in the appendix:

Lemma 1 Assume that $\alpha_{1} \alpha_{2}>0$ and (4) defines a unique function $\left(q_{1}, q_{2}\right) \rightarrow\left(p_{1}^{*}, p_{2}^{*}\right)$ in the neighborhood of $q_{1}=q_{2}=1$. Then this function is locally increasing in $q_{i}$, i.e. for $i \neq j \in\{1,2\}$ :

$$
\frac{\partial p_{i}^{*}}{\partial q_{i}}\left(q_{1}=q_{2}=1\right)>0 \text { and } \frac{\partial p_{i}^{*}}{\partial q_{j}}\left(q_{1}=q_{2}=1\right)>0
$$

Proof. In the appendix.

The result contained in this lemma is key to understanding a new source of incentives that the intermediary might have to divert search, relative to the case with exogenous store prices. Intuitively, a lower $q_{i}$ increases the proportion of "low-demand" consumers in the composition of traffic faced by each store (specifically, type $i$ consumers for store $j \neq i$ ), which puts downward pressure on equilibrium store prices. ${ }^{10}$

Turning now to the intermediary's profits and optimization problem, we still have:

$$
\begin{aligned}
\Pi^{I}\left(q_{1}, q_{2}\right)= & \underbrace{\alpha_{1}\left\{\left(r_{1}+r_{2}\right) F\left(u^{L}\left(p_{2}\right)\right)+\left[r_{1}+\left(1-q_{1}\right) r_{2}\right]\left[F\left(u\left(p_{1}, p_{2}, q_{1}\right)\right)-F\left(u^{L}\left(p_{2}\right)\right)\right]\right\}}_{\text {revenues from type } 1 \text { consumers }} \\
& +\underbrace{\alpha_{2}\left\{\left(r_{1}+r_{2}\right) F\left(u^{L}\left(p_{1}\right)\right)+\left[r_{2}+\left(1-q_{2}\right) r_{1}\right]\left[F\left(u\left(p_{2}, p_{1}, q_{2}\right)\right)-F\left(u^{L}\left(p_{1}\right)\right)\right]\right\}}_{\text {revenues from type } 2 \text { consumers }}
\end{aligned}
$$

The key difference with respect to the previous section is that now the levels of search effectiveness offered to the two types of consumers, $\left(q_{1}, q_{2}\right)$, have an additional and indirect effect on the

\footnotetext{
${ }^{9}$ Uniqueness is a technical condition. If it does not hold then the same result holds for any continuous selection of stable fixed points of (4). Uniqueness is verified if $F\left(u^{L}\left(p_{i}\right)\right) / F\left(u^{H}\left(p_{i}\right)\right)$ increases with $p_{i}$ or if $\arg \max _{p}\left\{R^{H}(p)+\beta R^{L}(p)\right\}$ does not decrease too fast with $\beta$.

${ }^{10}$ This conclusion would be unchanged if we allowed for a more general formulation, in which stores set a single price for their sales through the intermediary, as well as for sales that occur through other channels (e.g. store fronts on other platforms). In that case, it is reasonable to expect the "responsiveness" of store prices to the levels of search effectiveness $\left(\frac{d p_{i}^{*}}{d q_{i}}, \frac{d p_{i}^{*}}{d q_{j}}\right)$ will be reduced, but still positive.
} 
intermediary's profits through their impact on store prices:

$$
\frac{d \Pi^{I}}{d q_{i}}=\underbrace{\frac{\partial \Pi^{I}}{\partial q_{i}}}_{\text {same as before }}+\underbrace{\frac{\partial \Pi^{I}}{\partial p_{i}} \frac{d p_{i}^{*}}{d q_{i}}+\frac{\partial \Pi^{I}}{\partial p_{j}} \frac{d p_{j}^{*}}{d q_{i}}}_{\text {indirect effect of } q_{i} \text {, through store prices }}
$$

The sign of the direct effect $\frac{\partial \Pi^{I}}{\partial q_{i}}$ was determined/discussed in the previous section. In what follows we focus on determining the sign of the indirect effect in a neighborhood of $q_{1}=q_{2}=1$. We have: ${ }^{11}$

$$
\frac{\partial \Pi^{I}}{\partial p_{i}}\left(q_{1}=q_{2}=1\right)=\alpha_{i} r_{i} f\left(u^{H}\left(p_{i}^{*}\right)\right) \frac{d u^{H}\left(p_{i}^{*}\right)}{d p}+\alpha_{j} r_{i} f\left(u^{L}\left(p_{i}^{*}\right)\right) \frac{d u^{L}\left(p_{i}^{*}\right)}{d p}
$$

And, since the expected utility $u^{k}(p)$ decreases with price $p$ for $k=\{L, H\}$, we can conclude that:

$$
\frac{\partial \Pi^{I}}{\partial p_{i}}\left(q_{1}=q_{2}=1\right)<0
$$

Thus, everything else being equal, in a neighbourhood of $q_{1}=q_{2}=1$, the intermediary benefits from lower store prices since this raises total consumer traffic. Combined with lemma 2 and expression (5), this result leads to:

Proposition 2 Under the conditions of lemma 1, the intermediary diverts search when stores can adjust their prices after observing $\left(q_{1}, q_{2}\right)$ if the intermediary diverts search when store prices are exogenously fixed (to the levels which would prevail with endogenous store prices and $q_{1}=q_{2}=1$ ).

Proof. If the intermediary diverts search with exogenous prices then Proposition 1 implies that $\frac{\partial \Pi^{I}}{\partial q_{i}}<0$ at $q_{i}=1$. Furthermore, by lemma 1 and the last result above, we have $\frac{\partial \Pi^{I}}{\partial p_{i}} \frac{d p_{i}^{*}}{d q_{i}}+\frac{\partial \Pi^{I}}{\partial p_{j}} \frac{d p_{j}^{*}}{d q_{i}}<0$ (evaluated at $q_{1}=q_{2}=1$ ). Thus, (5) implies $\frac{d \Pi^{I}}{d p_{i}}\left(q_{1}=q_{2}=1\right)<0$ with endogenous store prices.

Thus search diversion is in a certain sense more profitable when prices are endogenous and stores react to the intermediary's design choice. The main reason for which the intermediary has further incentives to divert search with endogenous store prices is that each store fails to internalize the effect of its price on total consumer traffic to the intermediary (which includes traffic to the other store). Thus, stores tend to charge prices which are too high relative to what the intermediary would like. $^{12}$ This phenomenon is reminiscent of the "tragedy of the commons", with the intermediary playing the role of the "common" good and the stores being its users. The intermediary can mitigate

\footnotetext{
${ }^{11}$ Note indeed that: $u\left(p_{i}^{*}, p_{j}^{*}, 1\right)=u^{H}\left(p_{i}^{*}\right) ; \frac{\partial u\left(p_{i}, p_{j}, q_{i}\right)}{\partial p_{i}}=\frac{1}{2-q_{i}} \frac{d u^{H}\left(p_{i}\right)}{d p_{i}}$ and $\frac{\partial u\left(p_{j}, p_{i}, q_{j}\right)}{\partial p_{i}}=\frac{1-q_{j}}{2-q_{j}} \frac{d u^{L}\left(p_{i}\right)}{d p_{i}}$.

${ }^{12}$ In the companion paper we show that this result is robust when we change the nature of the variable fees received by the intermediary from stores from per-click (per visit) fees to per-sales fees.
} 
this problem by lowering $q_{1}$ and $q_{2}$, which increases the elasticity of total demand faced by each store.

\section{Can search diversion be replaced by other contractual instruments?}

Having identified two fundamental reasons for which an intermediary may design its information service in order to divert users' search, we now ask the natural question: could such an intermediary not achieve the same objective if it were allowed to use richer pricing and contracting instruments?

In this section we show that fully eliminating the need for search diversion requires the intermediary to use three additional pricing and contractual instruments: access fees and search subsidies on the consumer side, and price controls (or vertical integration) on the store side. Indeed, note that these instruments are targeted precisely at the two types of externalities, which are responsible for the intermediary's incentives to divert search. First consumers fail to internalize the positive

externality their decision to visit the intermediary bestows on the stores and therefore search "too little" (cf. section 3.1). Second, stores fail to fully internalize the effect of their pricing (or other strategic) decisions on total consumer traffic to the intermediary (cf. section 3.2).

\section{Access fees and search subsidies}

To squarely focus on the consumer-related externality, in this subsection we assume that store prices are exogenously fixed. By contrast with section 3.1 however, suppose that now the intermediary is able to both charge consumers of type $i$ a fee $A_{i} \geq 0$ and to offer them a subsidy $s_{i} \geq 0$ for performing a second search (independent of the identity of the store at which the second search is performed). For the online recommenders we have in mind, access fees can take the form of monthly registration fees, whereas search subsidies could be cash discounts offered to users at the stores to which they are directed by the intermediary (this is for example a distinctive feature of Bing Cashback).

Intuitively, the access fee should reduce the desirability of search diversion by raising the opportunity cost of the decrease in consumer traffic that diversion induces. The search subsidy also reduces the need to divert search by directly increasing consumers' utility from a second search and therefore expanding the set of consumers who search twice.

It is important to note however that neither one of these two instruments would be sufficient by itself to completely eliminate the need for search diversion. Consider first access fees in isolation. Recall that all consumers who use the intermediary visit their preferred store with probability 1 (either in the first or the second round of search). The net utility derived by a consumer from this visit only is $u^{H}\left(p_{i}\right)-A_{i}-c$, entailing revenue $r_{i}+A_{i}$ for the intermediary. An additional visit raises 
the consumer's surplus by $u^{L}\left(p_{j}\right)-c$ and generates additional revenue $r_{j}$ for the intermediary. Thus, for a given access fee $A_{i}$, the analysis of the incentives to divert search is the same as in section 3.1, simply replacing $\left(u^{H}\left(p_{i}\right), r_{i}\right)$ by $\left(u^{H}\left(p_{i}\right)-A_{i}, r_{i}+A_{i}\right)$, while $\left(u^{L}\left(p_{j}\right), r_{j}\right)$ are unchanged. ${ }^{13}$ The effect of the access fee is illustrated in the following figure:

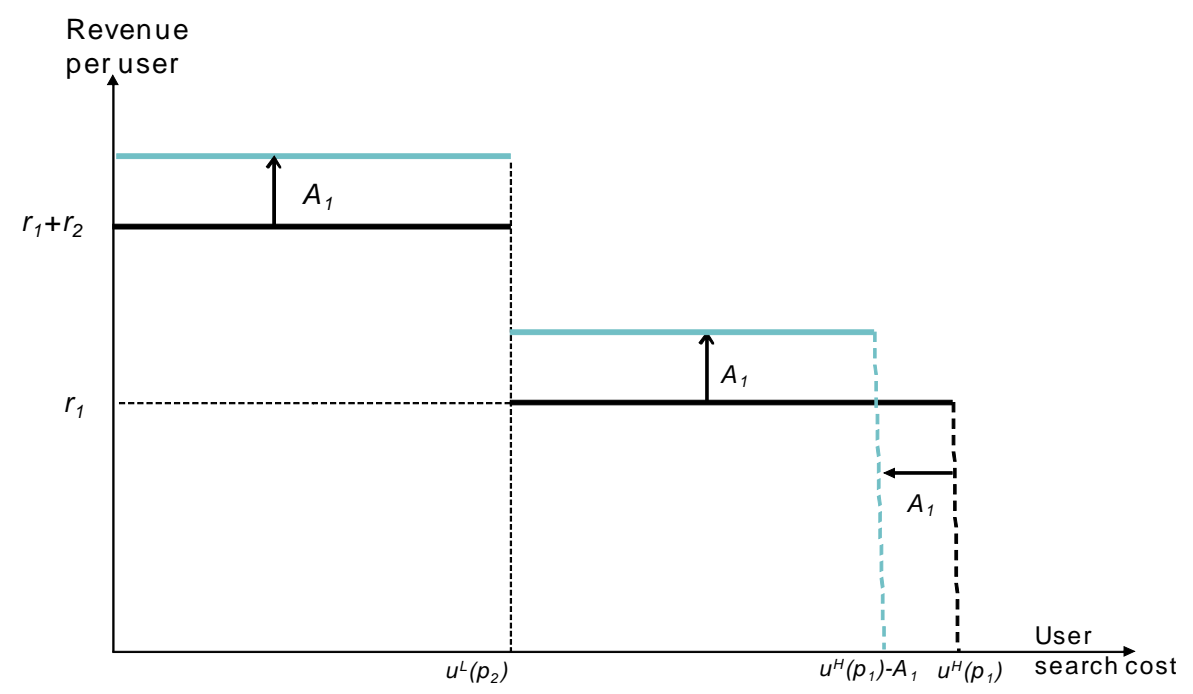

Consequently, the redistribution of consumer surplus from consumers' visit to their preferred store to the intermediary through access fees only will generally not be sufficient to induce $q_{i}^{*}=1$.

Second, consider search subsidies in isolation. It is easily seen that subsidizing type $i$ consumers' second search is equivalent to reducing the intermediary's revenue from type $i$ consumers visiting store $j$ from $r_{j}$ to $r_{j}-s_{i}$ and increasing the utility derived by type $i$ consumers from visiting store $j$ from $u^{L}\left(p_{j}\right)$ to $u^{L}\left(p_{j}\right)+s_{i}$ (thus, the number of type $i$ consumers who search twice increases from $F\left(u^{L}\left(p_{j}\right)\right)$ to $\left.F\left(u^{L}\left(p_{j}\right)+s_{i}\right)\right){ }^{14}$ The following figure illustrates the tradeoff faced by the intermediary when only a search subsidy is introduced:

\footnotetext{
${ }^{13}$ Conditional on $q_{i}=1$ and $s_{i}=0$, the profit maximizing access fee is $A_{i}^{*} \equiv \arg \max _{A}\left\{\left(r_{i}+A\right) F\left(u^{H}\left(p_{i}\right)-A\right)\right\}$

${ }^{14}$ Conditional on $q_{i}=1$ and $A_{i}=0$, the profit maximizing search subsidy is $s_{i}^{*} \equiv$ $\arg \max _{s}\left\{\left(r_{j}-s\right) F\left(u^{L}\left(p_{j}\right)+s\right)\right\}$.
} 


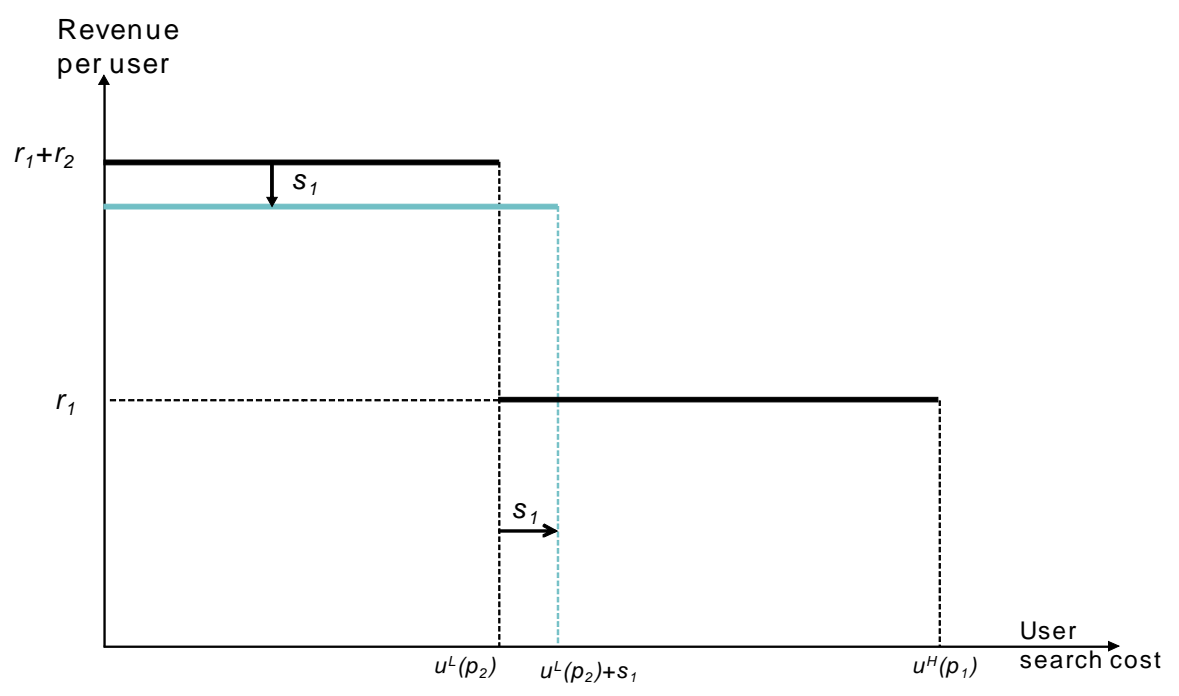

Thus, while a search subsidy tends to reduce the intermediary's incentives to divert search, it cannot entirely eliminate them by itself. Indeed, on the one hand, search subsidies entail a direct monetary cost for the platform, while on the other hand search diversion entails no direct monetary transfer but a cost in terms of lost participation. The two instruments are not substitutes.

Suppose now that the intermediary can use both access fees $A_{i}$ and second search subsidies $s_{i}$. Given that the access fees allow the intermediary to recoup the monetary cost of inducing more search by consumers through search subsidies, one would naturally conjecture that the combination of these two instruments should be enough to eliminate the need for search diversion. The following proposition confirms this intuition.

Proposition 3 With exogenous store prices, if the intermediary can use type-dependent access fees $A_{i}$ and second search subsidies $s_{i}$, then it finds it optimal not to divert search, i.e. $q_{i}^{*}=1$ for $i=1,2 .^{15}$

Proof. In the appendix.

The key to this result is the following. By having three instruments $\left(A_{i}, s_{i}, q_{i}\right)$ at its disposal for each consumer group, the intermediary is able to determine the two critical thresholds $v_{i} \equiv$ $u^{L}\left(p_{j}\right)+s_{i}$ (which separates consumers who always search twice and consumers who perform a second search with probability $q_{i}$ ) and $u_{i} \equiv \frac{u^{H}\left(p_{i}\right)+\left(1-q_{i}\right)\left(u^{L}\left(p_{j}\right)+s_{i}\right)-A_{i}}{2-q_{i}}$ (which separates consumers who search and those who do not visit the intermediary at all) independently of $q_{i}$ and of each

\footnotetext{
${ }^{15}$ Price discrimination among the two consumer groups is necessary to obtain the result because we have assumed that the intermediary can divert search in a discriminatory way. In the previous version of our working paper (HagiuJullien (2009)) we had developed a model with the same "search quality" $q$ for both consumer groups and shown that the result holds in that case without price-discrimination.
} 
other. ${ }^{16}$ These two additional degrees of freedom are sufficient for the intermediary to address the consumer-related externality (which is responsible for "too little" search) without resorting to search diversion and thereby degrading the quality of the information service provided (which reduces consumer traffic).

Price controls The analysis in the previous subsection addresses only the first motive for search diversion (cf. section 3.1), namely the search externality. As shown in section 3.2 however, when prices are endogenous, the intermediary may have an additional incentive to divert search: influencing stores' pricing decisions in order to limit the effect of ex-post opportunism (i.e. the one that arises because consumers do not observe store prices prior to making their search decisions). This second incentive disappears when the intermediary has direct control over store prices, which is equivalent to some form of vertical integration. The required level of vertical integration can range from outright ownership and control to vertical restraints under a contractual agreement between the intermediary and the stores.

Under complete vertical integration, the revenue derived by the intermediary from a store visit by a consumer depends not only on the identity of the store but also on the consumer's type: it is $R^{H}\left(p_{i}\right)$ for a consumer of type $i$ visiting store $i$ and $R^{L}\left(p_{j}\right)$ for a consumer of type $i$ visiting store $j$. The analysis of the incentives to divert search is then similar to the one in section 3.1, accounting for the fact that search diversion yields revenues which depend on consumers' types. The next proposition follows immediately:

Proposition 4 If the intermediary has full control and ownership of stores and can credibly announce store prices at the same time it announces $\left(q_{1}, q_{2}\right)$, then it diverts search for type $i$ consumers if:

$$
\frac{R^{L}\left(p_{j}^{*}\right)}{R^{H}\left(p_{i}^{*}\right)}>\frac{f\left(u^{H}\left(p_{i}^{*}\right)\right)\left(u^{H}\left(p_{i}^{*}\right)-u^{L}\left(p_{j}^{*}\right)\right)}{F\left(u^{H}\left(p_{i}^{*}\right)\right)-F\left(u^{L}\left(p_{j}^{*}\right)\right)}
$$

where

$$
\left(p_{1}^{*}, p_{2}^{*}\right) \equiv \arg \max _{p_{1}, p_{2}}\left\{\begin{array}{c}
\alpha_{1}\left[R^{L}\left(p_{2}\right) F\left(u^{L}\left(p_{2}\right)\right)+R^{H}\left(p_{1}\right) F\left(u^{H}\left(p_{1}\right)\right)\right] \\
+\alpha_{2}\left[R^{L}\left(p_{1}\right) F\left(u^{L}\left(p_{1}\right)\right)+R^{H}\left(p_{2}\right) F\left(u^{H}\left(p_{2}\right)\right)\right]
\end{array}\right\}
$$

are the profit-maximizing store prices conditional on choosing $q_{1}=q_{2}=1$.

Note that allowing the intermediary to directly control store prices eliminates the second motive for search diversion only if the intermediary can credibly communicate these prices to consumers before the latter make their participation and search decisions. To see that, suppose that store

\footnotetext{
${ }^{16}$ Indeed, the only restriction is $u_{i}>v_{i}$.
} 
prices are only observed by consumers when they arrive at the stores and that the interaction lasts only for one period (i.e. there are no reputation and learning effects). Then consumers' participation and search decisions depend only on anticipated prices. Since the actual prices chosen by the intermediary have no direct effect on search behavior, the pricing problem faced by the intermediary would be similar to the problem solved in section 3.2. This has two consequences. First the prices $\left(p_{1}^{*}, p_{2}^{*}\right)$ in Proposition 4 are now given by:

$$
\left(p_{1}^{*}, p_{2}^{*}\right) \equiv \arg \max _{p_{1}, p_{2}}\left\{\begin{array}{c}
\alpha_{1}\left[R^{L}\left(p_{2}\right) F\left(u^{L}\left(p_{2}^{*}\right)\right)+R^{H}\left(p_{1}\right) F\left(u^{H}\left(p_{1}^{*}\right)\right)\right] \\
+\alpha_{2}\left[R^{L}\left(p_{1}\right) F\left(u^{L}\left(p_{1}^{*}\right)\right)+R^{H}\left(p_{2}\right) F\left(u^{H}\left(p_{2}^{*}\right)\right)\right]
\end{array}\right\},
$$

and the condition provided there would only be sufficient. Second the same argument as in Proposition 2 applies: lowering $q_{i}$ reduces the prices anticipated by consumers. Thus, search diversion now serves as a way for the intermediary to solve its own time-inconsistency problem (the store prices it would like to commit to ex-ante are different from the prices it would like to charge ex-post).

Reputation mechanisms may provide a solution to the intermediary's commitment problem, but whenever imperfect, it will still have an additional motive to divert search by design, as a credible commitment device to charge lower prices.

\section{Discussion}

In the companion paper, we provide several variations of our basic model (per sales vs. per click fees; endogenous store entry; substitutability or complementarity between stores; stochastic and independent store values, etc.). These variations are meant to emphasize the general nature of the fundamental economic mechanism driving intermediaries' incentives to divert search that we have uncovered in this paper and to illustrate the flexibility of our basic model.

In this section, we briefly tackle three topics: the welfare implications of search diversion; the effect of competition between intermediaries on search diversion; other real-world applications of our model.

\subsection{Welfare and competition}

As mentioned ealier, search diversion can be interpreted as an attempt by intermediaries to address the following "market failure": consumers do not internalize the benefits bestowed on their potential trading partners - i.e. the stores - when they make their search decisions. This provides the first fundamental reason for which some search diversion may result in higher social welfare than none at all. 
To be precise, suppose that store prices are exogenously given. Note first that since the only consumers affected by search diversion are those who would not search voluntarily for their least preferred store, total consumer surplus (and traffic) is increasing in the effectiveness of search. Thus, from consumers' perspective, the monopoly level of search effectiveness $q_{i}^{*}$ is always too low - their surplus is maximized for $q_{i}^{C}=1$. Second, we know from the analysis in section 4 that total firm profits, i.e. the sum of the two stores' net profits plus the intermediary's profits, are maximized by $q_{i}^{S}<1$ if the condition of Proposition 4 is met. Therefore, it is possible that social welfare may be maximized by $q_{i}^{W}<1$ for at least one $i \in\{1,2\}$. In fact, it is straightforward to show that, with exogenously fixed store prices, maximizing social welfare requires diversion of type $i$ consumers if and only if:

$$
\frac{R^{L}\left(p_{j}\right)+u^{L}\left(p_{j}\right)-E\left(c \mid u^{L}\left(p_{j}\right) \leq c \leq u^{H}\left(p_{i}\right)\right)}{R^{H}\left(p_{i}\right)}>\frac{f\left(u^{H}\left(p_{i}\right)\right)\left[u^{H}\left(p_{i}\right)-u^{L}\left(p_{j}\right)\right]}{F\left(u^{H}\left(p_{i}\right)\right)-F\left(u^{L}\left(p_{j}\right)\right)}
$$

The interpretation of this condition is similar to that of (2), except that the social planner takes into account total store and consumer surplus, as well as the search costs incurred. Thus, lowering the effectiveness of search for type $i$ consumers by a small $\varepsilon$ below 1 has two effects on total social welfare. The first one is negative and corresponds to the loss of consumers with highest search costs. Since the marginal consumer is indifferent between participating or not, the first order welfare loss due to lower participation is simply the stores' profit loss, which is approximately $R^{H}\left(p_{i}\right) \varepsilon\left[u^{H}\left(p_{i}\right)-u^{L}\left(p_{j}\right)\right] f\left(u^{H}\left(p_{i}\right)\right)$. The second effect is positive and corresponds to the increase in total surplus generated by the fraction $\varepsilon$ of type $i$ consumers with $c \in\left[u^{L}\left(p_{j}\right), u_{i}(1-\varepsilon)\right]$ who now also visit store $j$. The mass of these consumers is approximately $\varepsilon\left[F\left(u^{H}\left(p_{i}\right)\right)-F\left(u^{L}\left(p_{j}\right)\right)\right]$, and the average total welfare gain per consumer in this group is $R^{L}\left(p_{j}\right)+u^{L}\left(p_{j}\right)$, net of their expected additional search costs, which are approximately $E\left(c \mid u^{L}\left(p_{j}\right) \leq c \leq u^{H}\left(p_{i}\right)\right)$. Comparing the relative magnitudes of these two effects yields (7). Note in particular that the left-hand side of (7) can be higher or lower than $\frac{r_{j}}{r_{i}}$, so that the monopoly intermediary may induce more or less search diversion than the social planner, depending on the structure of the revenues extracted from stores.

Suppose now that store prices are endogenous. If the social planner can choose both search effectiveness $\left(q_{1}, q_{2}\right)$ and store prices $\left(p_{1}, p_{2}\right)$, then it is easily seen that social welfare is maximized for $p_{1}=p_{2}=m$ (marginal cost) and $q_{1}=q_{2}=1$. If on the other hand the social planner cannot control store prices, ${ }^{17}$ then a (sufficient) condition for some search diversion of type $i$ consumers to be (constrained) welfare-maximizing is again $(7)$, except that $\left(p_{1}, p_{2}\right)$ are the (endogenous) equilibrium prices chosen by stores, conditional on $q_{1}=q_{2}=1$, and thus determined by equation (6) in section

\footnotetext{
${ }^{17}$ Either because it cannot observe costs or because these prices are determined taking into considerations other sales channels for the stores than the intermediary we consider here.
} 
4. ${ }^{18}$ Furthermore, Proposition 2 implies that even if condition 7 is violated, some search diversion may still improve social welfare (and possibly consumer surplus!) by lowering store prices.

The discussion above should also make it clear that introducing competition among intermediaries does not necessarily lead to $q_{i}=1$. In fact, stronger competitive intensity need not even increase $q_{i}$. To see this, consider the case with exogenous store prices. Note that the intermediaries we analyze act as "two-sided platforms" connecting consumers and stores. As explained above, with exogenously given store prices, consumers always prefer higher levels of search effectiveness (higher $q_{i}$ ). On the other hand, stores' gross profits are generally maximized for $q_{i}<1, i=1,2$. As a consequence, depending on the nature of competition between intermediaries - in particular on the intensity of competition for stores relative to the intensity of competition for consumers -, the resulting level of search effectiveness might place a higher weight on maximizing consumer surplus or stores' profits. In other words, given that two-sided platforms have to balance the interests of the two sides they serve, competition will tend to make the balance tilt in favor of the side that needs to be "courted" more assiduously by the intermediaries.

Suppose then that there are two stores - 1 and 2 - and two intermediaries - A and B - and consider two extreme cases. First, assume that both stores multihome, i.e. are accessible to consumers through both intermediaries. If intermediaries are undifferentiated from consumers' perspective and consumers only visit one intermediary, then intermediaries will focus their competitive efforts on the consumer side. They will set $q_{i}$ to maximize consumer surplus, which leads to $q_{i}^{*}=1 .^{19}$ Conversely, suppose now that stores only affiliate with one intermediary and that consumers can costlessly multihome, i.e. visit both intermediaries. Then competition will result in the maximization of store surplus, which generally requires $q_{i}^{*}<1$. In fact, depending on how one models the bargaining game between stores and intermediaries, it is quite possible that the equilibrium level of search effectiveness with competing intermediaries might be lower than that chosen by a monopoly intermediary.

\subsection{Other applications}

The model developed in the previous sections is inspired by and best fits independent online recommender sites such as Bing Cashback, Kaboodle and ThisNext.com. The fundamental economic mechanisms it uncovers are however very general and present in many industries - online and offline. In this subsection, we discuss the application of our model to several other prominent contexts.

\footnotetext{
${ }^{18}$ Or, equivalently, by equation (4) in section 3.2 with $q_{1}=q_{2}=1$.

${ }^{19}$ With Hotelling differentiation among intermediaries and unit transport costs $t$, we would expect to find: $q^{*}(t)<$ $1 ; \frac{d q^{*}}{d t}<0$.
} 


\subsubsection{Online and offline ad-supported media}

Consider the following advertising-supported intermediaries: search engines (e.g. Google, Ask.com), online portals (e.g. AOL, MSN, Yahoo!), print magazines (e.g. Esquire, Vanity Fair). All of these intermediaries can be thought of as offering users/readers access to two "stores": store 1 stands for "objective" search results and editorial content respectively, whereas store 2 stands for advertising (sponsored search and display ads respectively).

There are three common points which emerge when we apply our framework to analyze these intermediaries. First, the intermediary does not derive any revenues from store 1 (content or objective search results), i.e. $r_{1}=0$; instead, all of its revenues come from store 2, i.e. $r_{2}>0$. Second, the utility consumers derive from store 1 is not priced and can be assumed to be exogenously given - let us denote it by $u^{H}$. Similarly, a natural simplification is to assume that the utility consumers derive from store 2 (advertising) is also exogenously given and equal to $u^{L}$. Indeed, most of the sponsored ads on search engines, portals and magazines are about product awareness; and when they are about price, that price is likely set by advertisers independently of the intermediary we are focusing on. Third, it is reasonable to assume that all consumers are more interested in store 1 than in store $2,{ }^{20}$ so that $u^{H}>u^{L}$ and, implicitly, $\alpha_{1}=1, \alpha_{2}=0$.

As a consequence, there is only one variable $q$, which represents the ease with which consumers find what they are looking for through the intermediary - that is, store 1. The level of search effectiveness $q$ should be thought of as being determined by the relevant design decisions: the organization of the search results page (number and prominence of objective relative to sponsored search results); the layout and navigation structure of the portal web pages (ad views and clicks required to access the desired content); the layout of a print magazine (ease of access to table of contents and specific page numbers).

All of these intermediaries divert search to some extent. Some search engines exhibit sponsored search ads more prominently than others: for example, according to a search engine review, "in general, Ask's search-results pages are richer and better organized than typical Google results, and they give greater priority to content over ads" (Mossberg (2006)). Online portals intersperse advertisements throughout their content pages and sometimes split content across multiple pages in order to expose users to more ads. Finally, ad-supported magazines are notorious for making their tables of contents confusing and hard to find and split stories with numerous advertising pages.

The incentives to divert search come from the conflict faced by the intermediaries in serving their two sides (users and advertisers). Indeed, the value proposition to users is decreasing in the amount of search diversion, but that value cannot be monetized by the intermediary. Instead, its

\footnotetext{
${ }^{20}$ Allowing a fraction of consumers to be more interested in advertising and sponsored search results would only reinforce our results, i.e. the intermediary would have even more incentives to divert the group of consumers who place more value on objective results and editorial content.
} 
revenues come exclusively/mainly from advertisers, who benefit from search diversion.

To formalize this in the simplest possible way, suppose first $r_{2}$ is a constant, per click fee, as is the case with sponsored search results on search engines and some online portal advertising. In this case, the intermediary's revenues are proportional to store 2 traffic:

$$
\Pi^{I}=r_{2}\left\{F\left(u^{L}\right)+(1-q)\left[F\left(\frac{u^{H}+(1-q) u^{L}}{2-q}\right)-F\left(u^{L}\right)\right]\right\}
$$

It is straightforward to see that the intermediary always finds it optimal to divert search, i.e. $q^{*}<1$. Furthermore, if $u^{L}=0$, i.e. advertising has no value to users, then the profit-maximizing (interior) level of search diversion is given by $1-q^{*}=1 /\left(\varepsilon_{F}-1\right)$, where $\varepsilon_{F} \equiv \frac{u^{H}}{2-q^{*}} f\left(\frac{u^{H}}{2-q^{*}}\right) / F\left(\frac{u^{H}}{2-q^{*}}\right)$ can be interpreted as the elasticity of user traffic with respect to the quality of the search service offered. Naturally, the intermediary will induce less search diversion (i.e. increase $q^{*}$ ) when this elasticity is higher.

The other possibility is that advertisers pay a fee proportional to total consumer traffic to the intermediary, as is the case with some online portals and print magazines. Then, assuming rational expectations for advertisers, the intermediary's revenues are:

$$
\Pi^{I}=R(q) \times F\left(\frac{u^{H}+(1-q) u^{L}}{2-q}\right)
$$

where $R(q)$ is a decreasing function of $q$, i.e. increasing with the extent to which the intermediary diverts user search towards advertisers. Indeed, in this case advertisers are naturally willing to pay more per user who visits the intermediary when that user has a higher chance of being exposed to ads. At the extreme, if ads were all placed at the bottom of content webpages or grouped in the last pages of a print magazine (which would correspond to $q=1$ ), advertisers would likely not be willing to pay much for the service, i.e. $R(1) \simeq 0$. Again, under these assumptions, it is easily verified that $q^{*}<1$. If in addition $u^{L}=0$ then the profit-maximizing (interior) level of search diversion is determined by $1-q^{*}=1 /\left(\varepsilon_{F} / \varepsilon_{A}-1\right)$ where $\varepsilon_{F}$ is the elasticity of user traffic relative to the quality of the search and $\varepsilon_{A} \equiv-\left(1-q^{*}\right) R^{\prime}\left(q^{*}\right) / R\left(q^{*}\right)$ is the elasticity of ad revenues with respect to the degree of search diversion. Thus, as expected, the intermediary induces more search diversion when user traffic is less elastic and ad revenues are more elastic. 


\subsubsection{Shopping malls, department stores and retail stores}

Search diversion has also long been a prominent feature of offline retail intermediaries. Consider the following examples: ${ }^{21}$

- shopping mall developers place "anchor" stores as far from each other as possible and design the layout of the malls in such a way as to invite as much "exploration" as possible by visitors. ${ }^{22}$

- department stores put top of escalators arriving to one floor at the opposite end of bottom of escalator leading to the next floor

- retailers put the most popular products at the back or as far away from entrance as possible (e.g. milk and bread in supermarkets; iPods and iPhones in Apple stores; new movie releases in Blockbuster stores)

Our model can be easily adjusted to fit these three categories of intermediaries. Among themselves, they differ mainly in the degree of ownership and control of "stores" by the intermediary. Shopping malls are collections of independent stores operated by third parties (e.g. Wal-Mart, Zara). Department stores contain both retail spaces owned and operated by third-parties and spaces owned and operated by the department stores themselves. Finally, retailers own and control (in terms of inventory and pricing) most products that they offer on their shelves. In order to account for these various ownership scenarios, let us define generally $\widetilde{r}_{i j}$ as the revenues derived by the intermediary per consumer of type $j$ visiting store $i$. Then, using the notation introduced in

\footnotetext{
${ }^{21} \mathrm{~A}$ related example is airports. For example, Bristol Airport has undergone a physical reorganization during 2009, as a consequence of which travellers are now forced to walk through the duty-free shop in order to access the boarding gates.

${ }^{22}$ For instance, in a study of Roppongi Hills, Tokyo's most prominent shopping complex, Elberse Hagiu and Egawa (2008) report: "To convey a feeling of exploration akin to that found in real, organic cities, the architects opted for a maze-like structure in which visitors and residents could wander around for hours, and "discover" new shops and restaurants along the way. The structure was thought to benefit some of the lesser-known shops and restaurants, but some corporate tenants were less pleased with the lack of clarity that, they complained, confused their prospective employees."
} 
the previous sections, we have: ${ }^{23}$

$$
\widetilde{r}_{i j}=\left\{\begin{array}{cc}
r_{i} & \text { if store } i \text { is independent } \\
R^{H}\left(p_{i}\right) & \text { if store } i \text { is controlled by the } \\
& \text { intermediary and } i=j \\
R^{L}\left(p_{i}\right) & \begin{array}{c}
\text { if store } i \text { is controlled by the } \\
\text { intermediary and } i \neq j
\end{array}
\end{array}\right.
$$

The main difference relative to the online intermediaries that the model developed in sections 2 and 3 sought to represent is that offline (brick-and-mortar) intermediaries cannot fully discriminate the provision of their information services by consumer type. Indeed, their information services are largely determined by their physical design, which is by definition unique. This can be captured in our model by adding a technological constraint: ${ }^{24}$

$$
\Phi\left(q_{1}, q_{2}\right)=0
$$

For example, the layout of a shopping mall is determined once and for all when it is built, ${ }^{25}$ so that $\Phi$ takes the form $q_{1}=1-q_{2}$. On the other hand, retail shops can (and generally do) re-arrange the layout of their products often. Imagine for example that there are two products at two possible locations in the store. Locations are known from previous visits, but with probability $q$ the shop may all of a sudden invert the product locations. Each consumer would then go to the location where (s)he anticipates her/his favorite product to be, but would end up being diverted. The relevant constraint in this case is then $q_{1}=q_{2}=q$.

With these adjustments, we can readily use the same analysis as in section 3 to derive the expression of intermediary revenues, so that the latter maximizes:

$$
\begin{aligned}
\Pi^{I}\left(q_{1}, q_{2}\right)= & \underbrace{\alpha_{1}\left\{\left(\widetilde{r}_{11}+\widetilde{r}_{12}\right) F\left(u^{L}\left(p_{2}\right)\right)+\left[\widetilde{r}_{11}+\left(1-q_{1}\right) \widetilde{r}_{12}\right]\left[F\left(u_{1}\right)-F\left(u^{L}\left(p_{2}\right)\right)\right]\right\}}_{\text {revenues from type } 1 \text { consumers }} \\
& +\underbrace{\alpha_{2}\left\{\left(\widetilde{r}_{22}+\widetilde{r}_{21}\right) F\left(u^{L}\left(p_{1}\right)\right)+\left[\widetilde{r}_{22}+\left(1-q_{2}\right) \widetilde{r}_{21}\right]\left[F\left(u_{2}\right)-F\left(u^{L}\left(p_{1}\right)\right)\right]\right\}}_{\text {revenues from type } 2 \text { consumers }}
\end{aligned}
$$

\footnotetext{
${ }^{23} r_{i}$ stands for the percentage of sales that shopping malls and department stores charge to the third-party retailers that they "host".

Note that in the examples we focus on in this section, "store" can be either a retail shop in a mall or a department store or an actual product or product category in a retail store.

${ }^{24}$ Needless to say, this is a stark simplification with 2 stores. In reality, the main point remains that the levels of search effectiveness perceived by different consumer types are no longer independent of each other, but instead co-determined by the physical design technology.

${ }^{25}$ There are some exceptions. For instance, the developers of the Roppongi Hills complex in Tokyo have changed a quarter of the retail shops after only 2 years of operation.
} 
over $\left(q_{1}, q_{2}\right)$ subject to $(8)$.

The analysis is then similar, except for the adjustment of store/type-specific revenues $\tilde{r}_{i j}$ and for the physical design constraint. For instance, the case $q_{1}=q_{2}=q$ is treated in our 2009 working paper version and yields the same conclusions.

\section{Conclusion}

We have identified two fundamental sources of incentives for intermediaries to divert their users' search. The most basic one stems from a trade-off between higher user demand for (traffic to) the intermediary's information service and a higher number of searches per user visit. The second motive stems from the intermediary's incentives to control the strategic decisions of the stores that it provides access to. Each of these motives is related to an uninternalized externality: one on the user side (search decisions do not account for surplus of trading partners, i.e. stores) and one on the store side (strategic decisions do not account for the effect on overall user traffic to the intermediary).

Furthermore, we have shown that the incentives to divert search are quite resilient, in the sense that the set of contracting instruments available to the intermediary must be significantly enriched in order to fully eliminate them. Since most intermediaries do not have access to all necessary contractual instruments (ability to charge users fixed fees, to subsidize their search and to control store prices), our analysis suggests that search diversion is an essential strategic instrument for intermediaries and its use should be widespread. This is consistent with the numerous real-world instances of search diversion that we have pointed out in the previous section.

In this paper we have focused on new and original motives for search diversion. There might however be other motives, which stem from more traditional considerations. For instance, in our working paper version we have extended our model to the case where store affiliation with the intermediary is endogenous and contractual. In that case, when perfect discrimination among stores is not possible, the intermediary's profits place more weight on revenues extracted from marginal (less popular) stores relative to infra-marginal (more popular) stores. As a result the intermediary has an incentive to divert search toward marginal stores in order to reduce the differential in profits between marginal and infra-marginal stores (which enables the intermediary to raise the fees charged to all stores).

There are at least two very promising extensions of our model to explore in future research. ${ }^{26}$ Analyzing the effect of competition among intermediaries on the effectiveness of the search service

\footnotetext{
${ }^{26}$ Other simple extensions are provided in our companion paper.
} 
offered is the most immediate: we have provided some basic intuition in section 6.2 , but a formal analysis is warranted. Secondly, it would be interesting to build a dynamic setting, in which the quality of search $(q)$ is not known to consumers ex-ante, but some of them are repeat visitors. In this case, the intermediary has to take into account the fact that consumers form expectations of $q$ based on their past experience and use adequate decision rules to decide whether or not to visit again.

Finally, it is important to note that there exist other potential social benefits of search diversion, which are not directly captured in our model. An intriguing one is suggested by a recent study (Evans (2008)) of the impact of electronic publication on the way scholarly research is conducted. The key finding is that widespread electronic availability of journals and articles has made search too efficient, in the sense that scholars tend to "browse" and cite less and narrower material (the one closely related to the research at hand). By contrast, in the former print-only world, researchers were "forced" to browse more articles (perhaps less relevant a priori to what they were searching for in the first place), which may have resulted in a higher probability of novel and broader ideas. The author concludes that: "This research ironically intimates that one of the chief values of print library research is poor indexing. Poor indexing-indexing by titles and authors, primarily within core journals - likely had unintended consequences that assisted the integration of science

and scholarship. By drawing researchers through unrelated articles, print browsing and perusal may have facilitated broader comparisons and led researchers into the past."

We leave the formulation of a model that would explicitly capture this type of "serendipity" benefits of search diversion for future research.

\section{References}

[1] Avery, C., P. Resnick and R. Zeckhauser (1999) "The Market for Evaluations," American Economic Review, Vol. 89, No. 3., 564-584.

[2] Armstrong, M. (2006) "Competition in Two-Sided Markets," Rand Journal of Economics, Vol. 37 (3), 669-691.

[3] Armstrong M, Vickers J. and J. Zhou (2009) "Prominence and Consumers Search," Rand Journal of Economics, Vol. 40 , 209-233.

[4] Baye, M. and J. Morgan (2001) "Information Gatekeepers on the Internet and the Competitiveness of Homogeneous Product Markets," American Economic Review 91, 454-474.

[5] Biglaiser, G. (1993) "Middlemen As Experts," Rand Journal of Economics, Vol. 24, 212-223. 
[6] Caillaud, B., and B. Jullien (2001) "Competing Cybermediaries," European Economic Review, papers and proceedings, 45, 797-808.

[7] Caillaud, B., and B. Jullien (2003) "Chicken and Egg: Competition Among Intermediation Service Providers," Rand Journal of Economics, 34(2), 309-328.

[8] de Cornière, A. (2010) "Targeting with Consumer Search: an Economic Analysis of Keyword Advertising", mimeo, Paris School of Economics.

[9] Elberse, A., A. Hagiu and M. Egawa (2007) "Roppongi Hills: City Within A City," Harvard Business School Case Study 9-707-431.

[10] Ellison, G. and Ellison, S. F. (2009) "Search, Obfuscation, and Price Elasticities on the Internet," Econometrica, Vol. 77, No. 2, 427-452.

[11] Evans, D. S. (2003) "The Antitrust Economics of Multi-Sided Platform Markets," Yale Journal on Regulation, 20 (2), 325-82.

[12] Evans, J. A. (2008) "Electronic Publication and the Narrowing of Science and Scholarship," Science, Vol. 321, 395-399.

[13] Gehrig, T. (1993) "Intermediation in Search Markets," Journal of Economics and Management Strategy Vol. 2, 97-120.

[14] Hagiu, A. (2007) "Merchant or Two-Sided Platform?" Review of Network Economics, Vol. 6(2), $115-133$.

[15] Hagiu, A. and B. Jullien (2009) "Why Do Intermediaries Divert Search?" Harvard Business School and Toulouse School of Economics working paper version.

[16] Hagiu, A. and B. Jullien (2010) "Why Do Intermediaries Divert Search? - Companion Paper," Harvard Business School and Toulouse School of Economics working paper, available at http://www.people.hbs.edu/ahagiu/Hagiu\%20Jullien\%20companion\%04082010.pdf

[17] Hatfield, J. W. and P. R. Milgrom (2005) "Matching with Contracts," American Economic Review, Vol. 95 (4), 913-935.

[18] Hervas-Drane, A. (2007) "Word of Mouth and Recommender Systems: A Theory of the Long Tail," working paper, Harvard Business School.

[19] Kamenica, E. and M. Gentzkow (2009) "Bayesian Persuasion," working paper, University of Chicago. 
[20] Mossberg, W. (2006) "Personal Technology: Ask.com's new look scores big points versus rivals," Wall Street Journal, March 30, 2006.

[21] Parker, G. and M. W. Van Alstyne (2008) "Innovation, Openness and Platform Control," working paper, Tulane University, Boston University and MIT.

[22] Petroski, H. (2003) Small Things Considered: Why There Is No Perfect Design, New York: Knopf.

[23] Resnick, P. and H. R. Varian (1997) "Recommender Systems," Communications of the ACM, Vol. 40 (3).

[24] Rayo, L. and I. Segal (2009) "Optimal Information Disclosure," working paper, University of Chicago and Stanford University.

[25] Rochet, J.-C., and J. Tirole (2003) "Platform Competition in Two-Sided Markets," Journal of the European Economic Association, Vol. 1 (4), 990-1029.

[26] Rochet, J.-C., and J. Tirole (2006) "Two-Sided Markets: Where We Stand," Rand Journal of Economics, Vol. 37 (3), 645-66.

[27] Roth, A. E. (2002) "The Economist as Engineer: Game Theory, Experimentation, and Computation as Tools for Design Economics," Econometrica, Vol. 70 (4), 1341-1378.

[28] Roth, A. E. (2008) "What have we learned from market design?" Economic Journal, Vol. 118, 285-310.

[29] Roth, A. E. and M. Sotomayor (1990) Two-Sided Matching: A Study In Game-Theoretic Modeling and Analysis, Cambridge: Cambridge University Press.

[30] Rubinstein, A. and A. Wolinsky (1987) "Middlemen," Quarterly Journal of Economics, Vol. 102, 581-593.

[31] Rust, J. and G. Hall (2003), "Middlemen vs. Market Makers: A Theory of Competitive Exchange," Journal of Political Economy, Vol. 111 (2), 353-403.

[32] Shih, W., S. Kaufman and D. Spinola (2007) "Netflix," Harvard Business School case study 9-607-138.

[33] Spulber, D. F. (1996) "Market Microstructure and Intermediation," Journal of Economic Perspectives, Vol. 10 (3), 135-152. 
[34] Spulber, D. F. (2007) "Firms and Networks in Two-Sided Markets," The Handbook of Economics and Information Systems, Amsterdam: Elsevier.

[35] Stahl, B. (1988) "Bertrand Competition for Inputs and Walrasian Outcomes," The American Economic Review, Vol. 78, 189-201.

[36] White, A. (2008) "Search Engines: Left Side Quality versus Right Side Profits," working paper, Toulouse School of Economics.

\section{Appendix}

\section{Proof. of Proposition 1}

We start with the following lemma, which will prove useful below.

Lemma A1 The intermediary diverts type $i$ consumers (i.e. sets $q_{i}^{*}<1$ ) if and only if:

$$
\frac{r_{j}}{r_{i}}>\min _{u \in\left[\frac{u^{L}\left(p_{j}\right)+u^{H}\left(p_{i}\right)}{2}, u^{H}\left(p_{i}\right)\right]}\left(\frac{u-u^{L}\left(p_{j}\right)}{u^{H}\left(p_{i}\right)-u}\right)\left(\frac{F\left(u^{H}\left(p_{i}\right)\right)-F(u)}{F(u)-F\left(u^{L}\left(p_{j}\right)\right)}\right)
$$

Proof of Lemma A1 The intermediary does not divert type $i$ consumers if and only if, for all $q_{i} \in[0,1]:$

$$
\begin{gathered}
{\left[r_{i}+\left(1-q_{1}\right) r_{j}\right]\left[F\left(u_{i}\right)-F\left(u^{L}\left(p_{j}\right)\right)\right] \leq r_{i}\left[F\left(u^{H}\left(p_{i}\right)\right)-F\left(u^{L}\left(p_{j}\right)\right)\right]} \\
\Longleftrightarrow\left(1-q_{i}\right) \frac{r_{j}}{r_{i}} \leq \frac{F\left(u^{H}\left(p_{i}\right)\right)-F\left(u^{L}\left(p_{j}\right)\right)}{F\left(u_{i}\right)-F\left(u^{L}\left(p_{j}\right)\right)}-1 \\
\Longleftrightarrow \frac{r_{j}}{r_{i}} \leq \frac{1}{1-q_{i}} \frac{F\left(u^{H}\left(p_{i}\right)\right)-F\left(u_{i}\right)}{F\left(u_{i}\right)-F\left(u^{L}\left(p_{j}\right)\right)}
\end{gathered}
$$

But $\frac{1}{1-q_{i}}=\frac{u_{i}-u^{L}\left(p_{j}\right)}{u^{H}\left(p_{i}\right)-u_{i}}$ and when $q_{i}$ varies from 0 to $1, u_{i}$ varies from $\frac{u^{L}\left(p_{j}\right)+u^{H}\left(p_{i}\right)}{2}$ to $u^{H}\left(p_{i}\right)$ (the relationship between $q_{i}$ and $u_{i}$ is 1-to-1).

Part a) of Proposition 1 is easily proven by taking the first order condition of expression (1) in $q_{i}$, which can be written:

$$
\left[\frac{r_{i}}{r_{j}}+\left(1-q_{i}\right)\right] \frac{u^{H}\left(p_{i}\right)-u^{L}\left(p_{j}\right)}{\left(2-q_{i}\right)^{2}} f\left(u_{i}\right)-\left[F\left(u_{i}\right)-F\left(u^{L}\left(p_{j}\right)\right)\right]=0
$$


Since the left-hand side is increasing in $\frac{r_{i}}{r_{j}}$ and decreasing in $q_{i}$ (second order condition), it follows that $q_{i}^{*}$ is increasing in $\frac{r_{i}}{r_{j}}$.

For part b), the "if" is straightforward. Indeed, the derivative of the intermediary's revenues in $q_{i}$ evaluated at $q_{i}=1$ is:

$$
\frac{\partial \Pi^{I}}{\partial q_{i}}\left(q_{i}=1\right)=\alpha_{i}\left\{r_{i}\left[u^{H}\left(p_{i}\right)-u^{L}\left(p_{j}\right)\right] f\left(u^{H}\left(p_{i}\right)\right)-r_{j}\left[F\left(u^{H}\left(p_{i}\right)\right)-F\left(u^{L}\left(p_{j}\right)\right)\right]\right\}
$$

which is negative if $\frac{r_{j}}{r_{i}}>\frac{f\left(u^{H}\left(p_{i}\right)\right)\left(u^{H}\left(p_{i}\right)-u^{L}\left(p_{j}\right)\right)}{F\left(u^{H}\left(p_{i}\right)\right)-F\left(u^{L}\left(p_{j}\right)\right)}$. This implies that $q_{i}^{*}<1$.

The "only if" in part b) requires three steps.

Step 1 The log-concavity of $f$ implies that $\left(\frac{F\left(u^{H}\left(p_{i}\right)\right)-F(u)}{u^{H}\left(p_{i}\right)-u}\right)^{2} \geq f\left(u^{H}\left(p_{i}\right)\right) f(u)$ for all $u<u^{H}\left(p_{i}\right)$.

Proof of step 1 We wish to show that for all $u<u^{H}\left(p_{i}\right)$ :

$$
F\left(u^{H}\left(p_{i}\right)\right) \geq F(u)+\sqrt{f\left(u^{H}\left(p_{i}\right)\right) f(u)}\left(u^{H}\left(p_{i}\right)-u\right)
$$

The derivative of the right hand side in $u$ is:

$$
\begin{aligned}
& f(u)-\sqrt{f\left(u^{H}\left(p_{i}\right)\right) f(u)}+\frac{f^{\prime}(u)}{2} \sqrt{\frac{f\left(u^{H}\left(p_{i}\right)\right)}{f(u)}}\left(u^{H}\left(p_{i}\right)-u\right) \\
= & f(u) \sqrt{f\left(u^{H}\left(p_{i}\right)\right)}\left(\frac{1}{\sqrt{f\left(u^{H}\left(p_{i}\right)\right)}}-\frac{1}{\sqrt{f(u)}}+\frac{f^{\prime}(u)}{2 f(u) \sqrt{f(u)}}\left(u^{H}\left(p_{i}\right)-u\right)\right)
\end{aligned}
$$

Note that if $f(u)$ is log-concave then $\frac{1}{\sqrt{f(u)}}$ is convex in $u$. Indeed:

$$
\frac{\partial^{2}}{\partial u^{2}}\left(\frac{1}{\sqrt{f(u)}}\right)=\frac{\partial}{\partial u}\left(-\frac{f^{\prime}(u)}{2 f(u) \sqrt{f(u)}}\right)=-\frac{\partial}{\partial u}\left(\frac{f^{\prime}(u)}{f(u)}\right) \frac{1}{2 \sqrt{f(u)}}+\frac{f^{\prime}(u)^{2}}{4 f(u)^{2} \sqrt{f(u)}}>0
$$

But if $\frac{1}{\sqrt{f(u)}}$ convex then:

$$
\frac{1}{\sqrt{f\left(u^{H}\left(p_{i}\right)\right)}} \geq \frac{1}{\sqrt{f(u)}}-\frac{f^{\prime}(u)}{2 f(u) \sqrt{f(u)}}\left(u^{H}\left(p_{i}\right)-u\right)
$$

which implies that the RHS of inequality 9 is increasing in $u$. Since it is equal to the LHS at $u=u^{H}\left(p_{i}\right)$ and the LHS is constant in $u$, the proof of step 1 is complete. 
Step 2 For all $u \in\left[u^{L}\left(p_{j}\right), u^{H}\left(p_{i}\right)\right]$ we have:

$$
\left(\frac{u-u^{L}\left(p_{j}\right)}{u^{H}\left(p_{i}\right)-u}\right)\left(\frac{F\left(u^{H}\left(p_{i}\right)\right)-F(u)}{F(u)-F\left(u^{L}\left(p_{j}\right)\right)}\right) \geq \frac{f\left(u^{H}\left(p_{i}\right)\right)\left(u^{H}\left(p_{i}\right)-u^{L}\left(p_{j}\right)\right)}{F\left(u^{H}\left(p_{i}\right)\right)-F\left(u^{L}\left(p_{j}\right)\right)}
$$

Proof of step 2 The derivative in $u$ of the LHS of inequality (10) is:

$$
\begin{aligned}
& \frac{\partial}{\partial u}\left[\frac{u-u^{L}\left(p_{j}\right)}{F(u)-F\left(u^{L}\left(p_{j}\right)\right)} \frac{F\left(u^{H}\left(p_{i}\right)\right)-F(u)}{u^{H}\left(p_{i}\right)-u}\right] \\
= & \frac{\partial}{\partial u}\left[\left(\frac{u^{H}\left(p_{i}\right)-u^{L}\left(p_{j}\right)}{u^{H}\left(p_{i}\right)-u}-1\right)\left(\frac{F\left(u^{H}\left(p_{i}\right)\right)-F\left(u^{L}\left(p_{j}\right)\right)}{F(u)-F\left(u^{L}\left(p_{j}\right)\right)}-1\right)\right] \\
= & \frac{u^{H}\left(p_{i}\right)-u^{L}\left(p_{j}\right)}{\left(u^{H}\left(p_{i}\right)-u\right)^{2}}\left(\frac{F\left(u^{H}\left(p_{i}\right)\right)-F(u)}{F(u)-F\left(u^{L}\left(p_{j}\right)\right)}\right)-\left(\frac{u-u^{L}\left(p_{j}\right)}{u^{H}\left(p_{i}\right)-u}\right) \frac{F\left(u^{H}\left(p_{i}\right)\right)-F\left(u^{L}\left(p_{j}\right)\right)}{\left(F(u)-F\left(u^{L}\left(p_{j}\right)\right)^{2}\right.} f(u)
\end{aligned}
$$

Consider an extremum, i.e. a point $u$ where this derivative is equal to zero:

$$
\frac{u^{H}\left(p_{i}\right)-u^{L}\left(p_{j}\right)}{u^{H}\left(p_{i}\right)-u}\left(F\left(u^{H}\left(p_{i}\right)\right)-F(u)\right)=\left(u-u^{L}\left(p_{j}\right)\right) \frac{F\left(u^{H}\left(p_{i}\right)\right)-F\left(u^{L}\left(p_{j}\right)\right)}{F(u)-F\left(u^{L}\left(p_{j}\right)\right)} f(u)
$$

At this point, step 1 implies that:

$$
\begin{aligned}
\frac{u^{H}\left(p_{i}\right)-u^{L}\left(p_{j}\right)}{u^{H}\left(p_{i}\right)-u}\left(F\left(u^{H}\left(p_{i}\right)\right)-F(u)\right) \leq & \left(u-u^{L}\left(p_{j}\right)\right) \frac{F\left(u^{H}\left(p_{i}\right)\right)-F\left(u^{L}\left(p_{j}\right)\right)}{F(u)-F\left(u^{L}\left(p_{j}\right)\right)} \\
& \times\left(\frac{F\left(u^{H}\left(p_{i}\right)\right)-F(u)}{u^{H}\left(p_{i}\right)-u}\right)^{2} \frac{1}{f\left(u^{H}\left(p_{i}\right)\right)}
\end{aligned}
$$

which can be re-written:

$$
\left(\frac{u-u^{L}\left(p_{j}\right)}{u^{H}\left(p_{i}\right)-u}\right)\left(\frac{F\left(u^{H}\left(p_{i}\right)\right)-F(u)}{F(u)-F\left(u^{L}\left(p_{j}\right)\right)}\right) \geq \frac{f\left(u^{H}\left(p_{i}\right)\right)\left(u^{H}\left(p_{i}\right)-u^{L}\left(p_{j}\right)\right)}{F\left(u^{H}\left(p_{i}\right)\right)-F\left(u^{L}\left(p_{j}\right)\right)}
$$

We have thus shown that any extremum of $\left(\frac{u-u^{L}\left(p_{j}\right)}{F(u)-F\left(u^{L}\left(p_{j}\right)\right)}\right)\left(\frac{F\left(u^{H}\left(p_{i}\right)\right)-F(u)}{u^{H}\left(p_{i}\right)-u}\right)$ is no smaller than $\frac{f\left(u^{H}\left(p_{i}\right)\right)\left(u^{H}\left(p_{i}\right)-u^{L}\left(p_{j}\right)\right)}{F\left(u^{H}\left(p_{i}\right)\right)-F\left(u^{L}\left(p_{j}\right)\right)}$.

Furthermore, evaluating $\left(\frac{u-u^{L}\left(p_{j}\right)}{F(u)-F\left(u^{L}\left(p_{j}\right)\right)}\right)\left(\frac{F\left(u^{H}\left(p_{i}\right)\right)-F(u)}{u^{H}\left(p_{i}\right)-u}\right)$ at $u=u^{L}\left(p_{j}\right)$ and $u=u^{H}\left(p_{i}\right)$, we obtain $\frac{1}{f\left(u^{L}\left(p_{j}\right)\right)}\left(\frac{F\left(u^{H}\left(p_{i}\right)\right)-F\left(u^{L}\left(p_{j}\right)\right)}{u^{H}\left(p_{i}\right)-u^{L}\left(p_{j}\right)}\right)$ and $\frac{f\left(u^{H}\left(p_{i}\right)\right)\left(u^{H}\left(p_{i}\right)-u^{L}\left(p_{j}\right)\right)}{F\left(u^{H}\left(p_{i}\right)\right)-F\left(u^{L}\left(p_{j}\right)\right)}$ respectively, both of which are greater than or equal to $\frac{f\left(u^{H}\left(p_{i}\right)\right)\left(u^{H}\left(p_{i}\right)-u^{L}\left(p_{j}\right)\right)}{F\left(u^{H}\left(p_{i}\right)\right)-F\left(u^{L}\left(p_{j}\right)\right)}$ by step 1 . 
Consequently, condition (10) is verified for all $u \in\left[u^{L}\left(p_{j}\right), u^{H}\left(p_{i}\right)\right]$.

Step 3 Suppose now that the intermediary diverts type $i$ customers. Then, by lemma A1:

$$
\frac{r_{j}}{r_{i}}>\min _{u \in\left[\frac{u^{L}\left(p_{j}\right)+u^{H}\left(p_{i}\right)}{2}, u^{H}\left(p_{i}\right)\right]}\left\{\left(\frac{u-u^{L}\left(p_{j}\right)}{u^{H}\left(p_{i}\right)-u}\right)\left(\frac{F\left(u^{H}\left(p_{i}\right)\right)-F(u)}{F(u)-F\left(u^{L}\left(p_{j}\right)\right)}\right)\right\}
$$

which, combined with step 2, implies:

$$
\frac{r_{j}}{r_{i}}>\frac{f\left(u^{H}\left(p_{i}\right)\right)\left(u^{H}\left(p_{i}\right)-u^{L}\left(p_{j}\right)\right)}{F\left(u^{H}\left(p_{i}\right)\right)-F\left(u^{L}\left(p_{j}\right)\right)}
$$

Part c) of Proposition 1:

- If $F$ is concave then for all $u \in\left(u^{L}\left(p_{j}\right), u^{H}\left(p_{i}\right)\right)$ :

$$
\left(\frac{u-u^{L}\left(p_{j}\right)}{u^{H}\left(p_{i}\right)-u}\right)\left(\frac{F\left(u^{H}\left(p_{i}\right)\right)-F(u)}{F(u)-F\left(u^{L}\left(p_{j}\right)\right)}\right) \leq 1
$$

Then, since either $\frac{r_{1}}{r_{2}} \geq 1$ or $\frac{r_{2}}{r_{1}} \geq 1$, lemma A1 implies that at least one of the two consumer types is diverted.

- If $F$ is convex then for all $u \in\left(u^{L}\left(p_{j}\right), u^{H}\left(p_{i}\right)\right)$ :

$$
\left(\frac{u-u^{L}\left(p_{j}\right)}{u^{H}\left(p_{i}\right)-u}\right)\left(\frac{F\left(u^{H}\left(p_{i}\right)\right)-F(u)}{F(u)-F\left(u^{L}\left(p_{j}\right)\right)}\right) \geq 1
$$

Using lemma A1 again, it follows that at least one of the two customer groups is not diverted.

\section{Proof. of Lemma 1}

Let $\phi(\beta) \equiv \arg \max _{p}\left\{R^{H}(p)+R^{L}(p) \beta\right\}$. Clearly, $\phi(\beta) \in\left[p^{L}, p^{H}\right]$. On this range $R^{L}($.$) is$ decreasing while $R^{H}($.$) is increasing. In particular \frac{\partial^{2}}{\partial \beta \partial p}\left(R^{H}(p)+R^{L}(p) \beta\right)=\frac{\partial}{\partial p}\left(R^{L}(p)\right)<0$. This implies that $\phi(\beta)$ is decreasing.

Let

$$
\beta_{i} \equiv \frac{\alpha_{j}\left[q_{j} F\left(u^{L}\left(p_{i}\right)\right)+\left(1-q_{j}\right) F\left(\frac{u^{H}\left(p_{j}\right)+\left(1-q_{j}\right) u^{L}\left(p_{i}\right)}{2-q_{j}}\right)\right]}{\alpha_{i} F\left(\frac{u^{H}\left(p_{i}\right)+\left(1-q_{i}\right) u^{L}\left(p_{j}\right)}{2-q_{i}}\right)}
$$


Then (4) can be rewritten as:

$$
\begin{aligned}
& p_{i}^{*}=\phi\left(\beta_{i}\right) \\
& \beta_{i}=\beta\left(p_{1}^{*}, p_{2}^{*}, q_{1}, q_{2}\right)
\end{aligned}
$$

Notice that $\beta_{i}$ is continuously diffferentiable. We then have:

$$
\begin{gathered}
\frac{\partial \beta_{i}}{\partial q_{j}}=\frac{\alpha_{j}}{\alpha_{i}}\left(\frac{F\left(u^{L}\left(p_{i}\right)\right)-F\left(\frac{u^{H}\left(p_{j}\right)+\left(1-q_{j}\right) u^{L}\left(p_{i}\right)}{2-q_{j}}\right)+\left(1-q_{j}\right) \frac{\partial}{\partial q_{j}}\left(F\left(\frac{u^{H}\left(p_{j}\right)+\left(1-q_{j}\right) u^{L}\left(p_{i}\right)}{2-q_{j}}\right)\right)}{F\left(\frac{u^{H}\left(p_{i}\right)+\left(1-q_{i}\right) u^{L}\left(p_{j}\right)}{2-q_{i}}\right)}\right) \\
\frac{\partial \beta_{i}}{\partial q_{i}}=-\beta_{i}\left(\frac{\frac{\partial}{\partial q_{i}}\left(F\left(\frac{u^{H}\left(p_{i}\right)+\left(1-q_{i}\right) u^{L}\left(p_{j}\right)}{2-q_{i}}\right)\right)}{F\left(\frac{u^{H}\left(p_{i}\right)+\left(1-q_{i}\right) u^{L}\left(p_{j}\right)}{2-q_{i}}\right)}\right)<0
\end{gathered}
$$

At $q_{1}=q_{2}=1$ we then have:

$$
\frac{\partial \beta_{i}}{\partial q_{j}}=\frac{\alpha_{j}}{\alpha_{i}}\left(\frac{F\left(u^{L}\left(p_{i}\right)\right)-F\left(u^{H}\left(p_{j}\right)\right)}{F\left(u^{H}\left(p_{i}\right)\right)}\right)<0 \text { and } \frac{\partial \beta_{1}}{\partial q_{1}}<0
$$

We also have $\beta_{i} \equiv \frac{\alpha_{j} F\left(u^{L}\left(p_{i}\right)\right)}{\alpha_{i} F\left(u^{H}\left(p_{i}\right)\right)}$ and thus $\frac{\partial \beta_{i}}{\partial q_{j}}=0$. Notice that our assumptions imply that $\phi$ is differentiable and since the equilibrium prices $p_{i}^{*}$ are uniquely defined, the implicit function theorem implies:

$$
\left(1-\frac{d \phi\left(\beta_{i}\right)}{d \beta_{i}} \frac{\partial \beta_{i}}{\partial p_{i}}\right) \frac{d p_{i}^{*}}{d q_{1}}=\frac{d \phi\left(\beta_{i}\right)}{d \beta_{i}}\left(\frac{\partial \beta_{i}}{\partial q_{1}}\right)
$$

Moreover the uniqueness condition for $p_{i}^{*}$ implies $1>\left|\frac{d \phi}{d \beta_{i}} \frac{\partial \beta_{i}}{\partial p_{i}}\right|$. To see that notice that at $q_{1}=q_{2}=1$, $\beta_{i}$ is only a function of $p_{i}$, and $p_{i}^{*}$ solves $p_{i}^{*}=\phi\left(\beta_{i}\left(p_{i}^{*}, 1,1\right)\right)$. Moreover $\phi\left(\beta_{i}\right) \in\left(p^{L}, p^{H}\right)$, thus the fixed point is unique iff $1>\left|\frac{d \phi}{d \beta_{i}} \frac{\partial \beta_{i}}{\partial p_{i}}\right| \cdot{ }^{27}$

We can therefore conclude that $\frac{d p_{i}^{*}}{d q_{1}}>0$.

\section{Proof. of Proposition 3}

For concision, we focus on the search quality provided to type $i$ consumers, $q_{i}$. Indeed, the intermediary's revenues can be split into revenues coming from each consumer type, such that revenues from type $i$ only depend on the variables relevant to type $i$, i.e. $\left(A_{i}, s_{i}, q_{i}\right)$.

If $u^{L}\left(p_{j}\right)+s_{i} \leq u^{H}\left(p_{i}\right)-A_{i}$ then $u^{L}\left(p_{j}\right)+s_{i} \leq \frac{u^{H}\left(p_{i}\right)+\left(1-q_{i}\right)\left(u^{L}\left(p_{j}\right)+s_{i}\right)-A_{i}}{2-q_{i}}$, so that the marginal type $i$ consumer visiting the intermediary is unwilling to visit his least preferred store as a second-

\footnotetext{
${ }^{27}$ We rule out the case of equality where the same conclusion holds but using small differences.
} 
round search. In this case, the intermediary's revenues derived from type $i$ consumers are:

$$
\begin{gathered}
\Pi_{i}^{I}\left(A_{i}, s_{i}, q_{i}\right)=\alpha_{i}\left(r_{i}+r_{j}+A_{i}-s_{i}\right) F\left(u^{L}\left(p_{j}\right)+s_{i}\right)+ \\
+\alpha_{i}\left[r_{i}+A_{i}+\left(1-q_{i}\right)\left(r_{j}-s_{i}\right)\right]\left[F\left(\frac{u^{H}\left(p_{i}\right)+\left(1-q_{i}\right)\left(u^{L}\left(p_{j}\right)+s_{i}\right)-A_{i}}{2-q_{i}}\right)-F\left(u^{L}\left(p_{j}\right)+s_{i}\right)\right]
\end{gathered}
$$

If $u^{L}\left(p_{j}\right)+s_{i} \geq u^{H}\left(p_{i}\right)-A_{i}$ then $u^{L}\left(p_{j}\right)+s_{i} \geq \frac{u^{H}\left(p_{i}\right)+\left(1-q_{i}\right)\left(u^{L}\left(p_{j}\right)+s_{i}\right)-A_{i}}{2-q_{i}}$, so that all type $i$ consumers who visit the intermediary visit both stores with probability 1 . In this case, the intermediary's revenues derived from type $i$ consumers are:

$$
\Pi_{i}^{I N T}\left(A_{i}, s_{i}, q_{i}\right)=\alpha_{i}\left(r_{i}+r_{j}+A_{i}-s_{i}\right) F\left(\frac{u^{H}\left(p_{i}\right)+u^{L}\left(p_{j}\right)+s_{i}-A_{i}}{2}\right)
$$

If at the optimum $u^{L}\left(p_{j}\right)+s_{i}^{*} \geq u^{H}\left(p_{i}\right)-A_{i}^{*}$ then $q_{i}=1$ is weakly optimal. Suppose then that $u^{L}\left(p_{j}\right)+s_{i}^{*}<u^{H}\left(p_{i}\right)-A_{i}^{*}$.

To simplify calculations, let us make the following change of variables:

$$
\left(A_{i}, s_{i}, q_{i}\right) \rightarrow\left(\begin{array}{c}
v_{i} \equiv u^{L}\left(p_{j}\right)+s_{i} \\
u_{i} \equiv \frac{u^{H}\left(p_{i}\right)+\left(1-q_{i}\right)\left(u^{L}\left(p_{j}\right)+s_{i}\right)-A_{i}}{2-q_{i}} \\
q_{i}
\end{array}\right)
$$

It is easily seen that this change of variables is 1-to-1 $\left(\left(A_{i}, s_{i}, q_{i}\right)\right.$ define a unique $\left(v_{i}, u_{i}, q_{i}\right)$ and viceversa). Therefore, optimizing the intermediary's revenues over $\left(A_{i}, s_{i}, q_{i}\right)$ is equivalent to optimizing over $\left(v_{i}, u_{i}, q_{i}\right)$. Furthermore, the condition $u^{L}\left(p_{j}\right)+s_{i}^{*}<u^{H}\left(p_{i}\right)-A_{i}^{*}$ is equivalent to $u_{i}^{*}>v_{i}^{*}$. For $u_{i}>v_{i}$ we have:

$$
\frac{\Pi_{i}^{I}\left(v_{i}, u_{i}, q_{i}\right)}{\alpha_{i}}=q_{i}\left[u^{L}\left(p_{j}\right)+r_{j}-v_{i}\right] F\left(v_{i}\right)+\left[u^{H}\left(p_{i}\right)+r_{i}+\left(1-q_{i}\right)\left(u^{L}\left(p_{j}\right)+r_{j}\right)-\left(2-q_{i}\right) u_{i}\right] F\left(u_{i}\right)
$$

and therefore:

$$
\frac{\partial \prod_{i}^{I}\left(v_{i}, u_{i}, q_{i}\right)}{\partial q_{i}} \frac{1}{\alpha_{i}}=\left[u^{L}\left(p_{j}\right)+r_{j}-v_{i}\right] F\left(v_{i}\right)+\left[u_{i}-u^{L}\left(p_{j}\right)-r_{j}\right] F\left(u_{i}\right)
$$

But $u_{i}^{*}>v_{i}^{*}$ means that the first order conditions in $\left(v_{i}, u_{i}\right)$ must hold at the global optimum. Thus:

$$
\begin{gathered}
v_{i}^{*}+\frac{F\left(v_{i}^{*}\right)}{f\left(v_{i}^{*}\right)}=u^{L}\left(p_{j}\right)+r_{j} \\
\frac{u^{H}\left(p_{i}\right)+r_{i}+\left(1-q_{i}^{*}\right)\left(u^{L}\left(p_{j}\right)+r_{j}\right)}{2-q_{i}^{*}}=u_{i}^{*}+\frac{F\left(u_{i}^{*}\right)}{f\left(u_{i}^{*}\right)}
\end{gathered}
$$


We obtain:

$$
\frac{1}{\alpha_{i}} \frac{\partial \Pi_{i}^{I}}{\partial q_{i}}\left(v_{i}^{*}, u_{i}^{*}, q_{i}^{*}\right)=\frac{F^{2}\left(v_{i}^{*}\right)}{f\left(v_{i}^{*}\right)}+\left(u_{i}^{*}-v_{i}^{*}-\frac{F\left(v_{i}^{*}\right)}{f\left(v_{i}^{*}\right)}\right) F\left(u_{i}^{*}\right)
$$

But note that:

$$
\begin{aligned}
\frac{\partial}{\partial u_{i}^{*}}\left[\frac{F^{2}\left(v_{i}^{*}\right)}{f\left(v_{i}^{*}\right)}+\left(u_{i}^{*}-v_{i}^{*}-\frac{F\left(v_{i}^{*}\right)}{f\left(v_{i}^{*}\right)}\right) F\left(u_{i}^{*}\right)\right] & =F\left(u_{i}^{*}\right)+\left(u_{i}^{*}-v_{i}^{*}-\frac{F\left(v_{i}^{*}\right)}{f\left(v_{i}^{*}\right)}\right) f\left(u_{i}^{*}\right) \\
& =f\left(u_{i}^{*}\right)\left(\frac{F\left(u_{i}^{*}\right)}{f\left(u_{i}^{*}\right)}+u_{i}^{*}-v_{i}^{*}-\frac{F\left(v_{i}^{*}\right)}{f\left(v_{i}^{*}\right)}\right)
\end{aligned}
$$

Since the density $f$ is log-convave, the c.d.f. $F$ is also log-concave (Bagnoli-Bergstrom (2005)). Thus $\frac{F\left(u_{i}^{*}\right)}{f\left(u_{i}^{*}\right)}+u_{i}^{*}$ is increasing and positive for $u_{i}^{*}>v_{i}^{*}$. It follows that $\frac{\partial \Pi_{i}^{I}}{\partial q_{i}}\left(v_{i}^{*}, u_{i}^{*}, q_{i}^{*}\right)$ is strictly positive, which implies that at the optimum we must have $q_{i}^{*}=1$. 